This article has been scanned by iThenticat No plagiarism detected

Volume 3, Issue 2, April 2021

p. $109-120$

\title{
GRAMMATICAL STRUCTURE AND ITS EFFECT ON CHANGING THE LEXICAL SIGNIFICANCE
}

http://dx.doi.org/10.47832/2757-5403.2-3.10

\section{Azza Adnan Ahmed EZZAT ${ }^{1}$ \& Gayda Adiel Abed ALKADIR ${ }^{2}$}

\begin{abstract}
:
The renewal in the lexical study depends on looking at the expressions and connotations it contains that are influenced by the context of what they are mentioned in as much as it relates to linguistic matters, such as changing the morphological form, or the multiplicity of the form of the source of the verb, or the construction of active voice and passive voice, or the infringement and imperative as well as the type of preposition infringement To come up with multiple connotations that correspond to those changes that are directly related to the context and what we can call (the semantic attribution) that is different from the grammatical attribution. In it, the connotation changes by changing the type of the subject or the predicate from masculine to feminine, and from singular to dual or plural, and from rational to non-rational, and from material to semantic or abstract to concrete and the like. According to all the above, it is not correct to separate the linguistic levels in any integrated linguistic study.
\end{abstract}

Key words: Semantics, Morphological Syntax, Lexicon Of Metrics, Semantic Received: $8 / 03 / 2021$ Change.
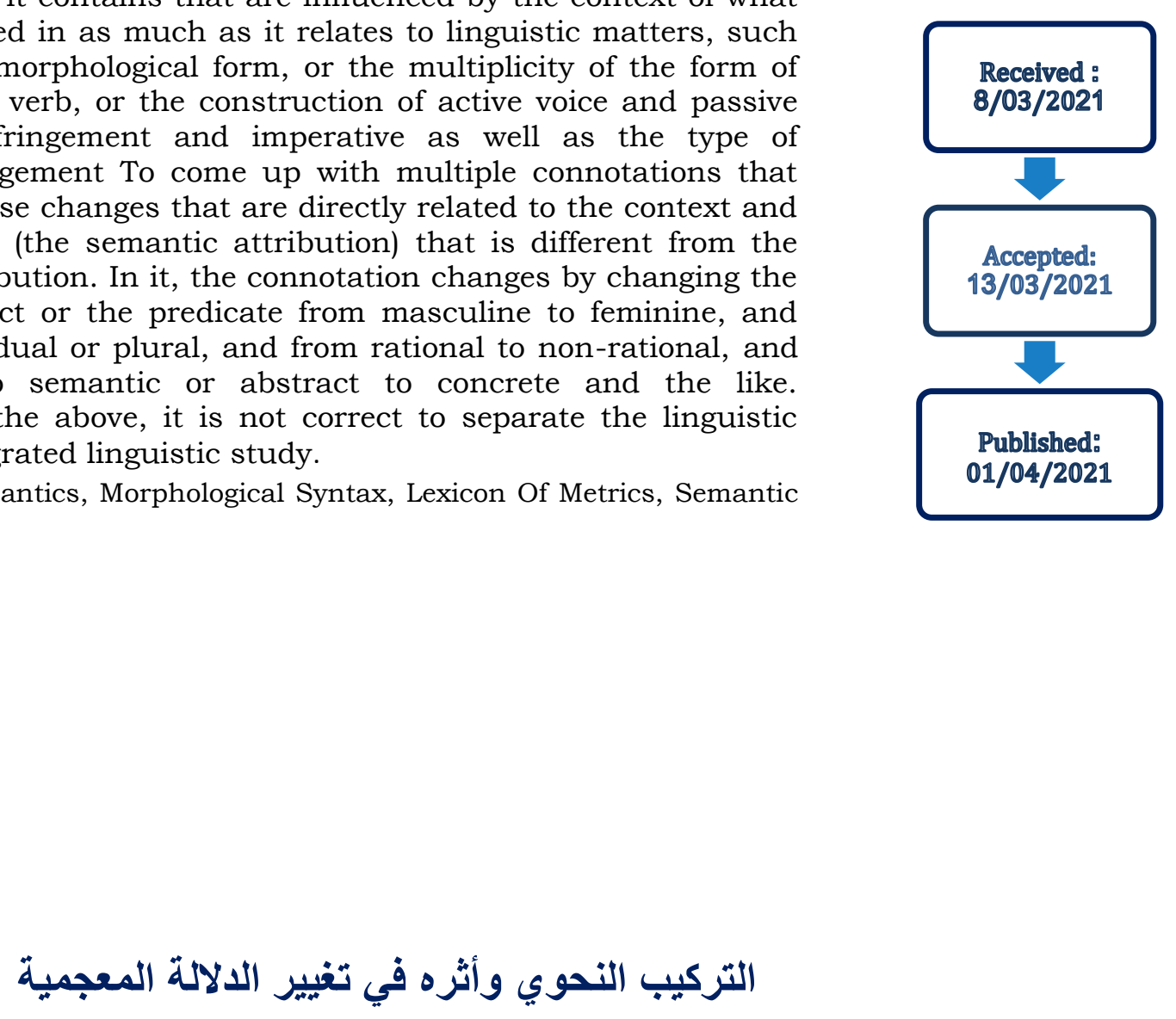

\footnotetext{
${ }^{1}$ Prof. Dr. , Zakho University, Iraq, azza.ezzat@uoz.edu.krd, https://orcid.org/0000-0001-6648-3330

${ }^{2}$ Researcher, Directorate of Education in the province of Dohuk, Iraq
} 


\title{
عزّة عدنان أحمد عزّت

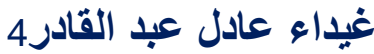

\begin{abstract}
الملخص

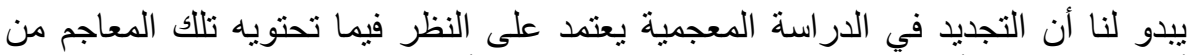

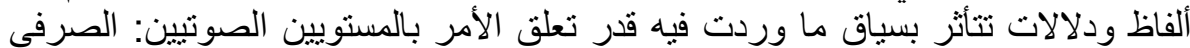

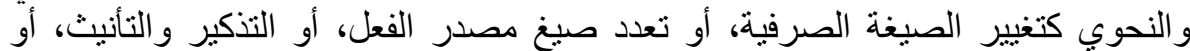

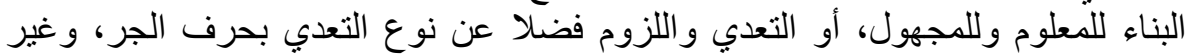

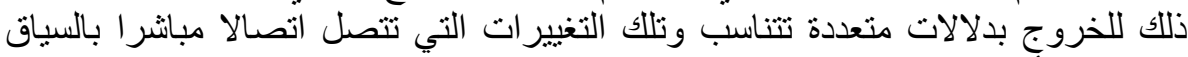

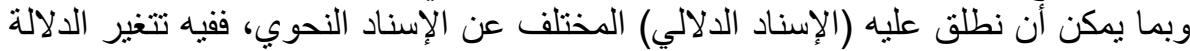

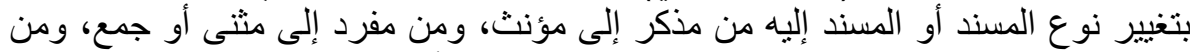

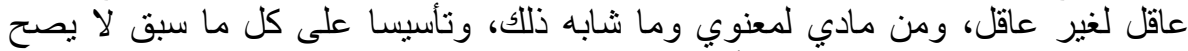

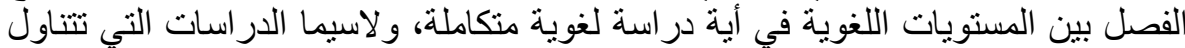

الدلالة.

الكلمات المفتاحية: الدلالة، الصيغة الصرفية، معجم المقاييس، التغيير الدلالي.
\end{abstract}

تربط دراستتا (التركيب النحوي وأثره في تغيير الدلالة المعجمية) دلالة المستوى المعجمي بدلالة المستوى النحوي

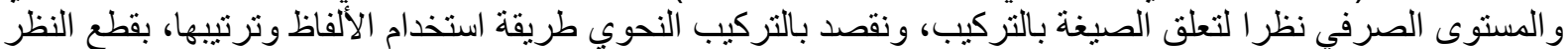

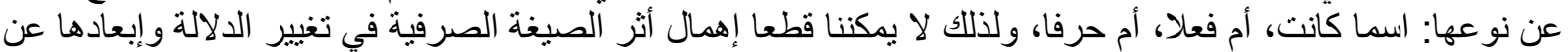

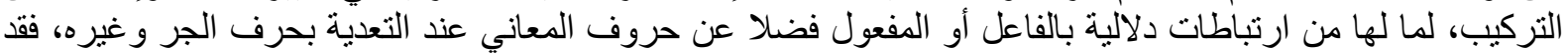

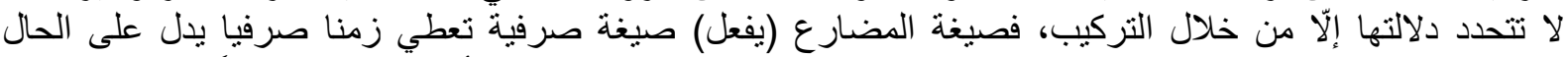

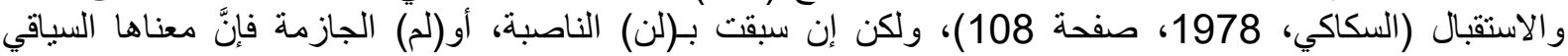

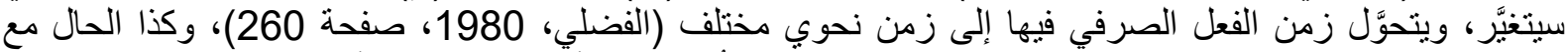

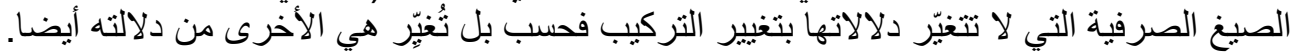

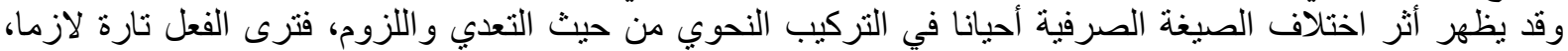

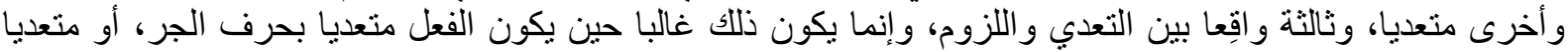

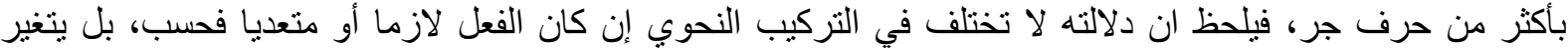

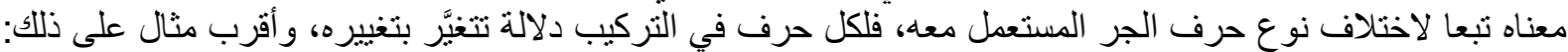

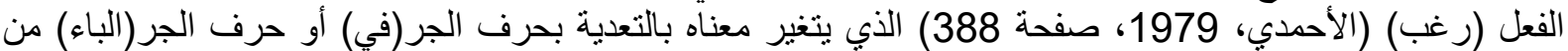

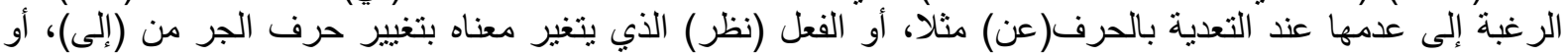

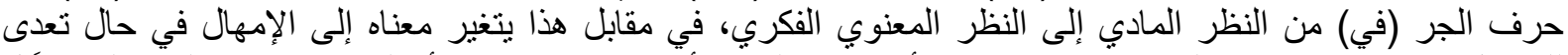

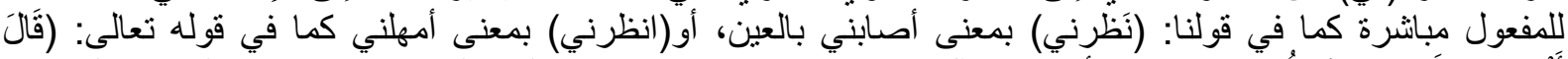

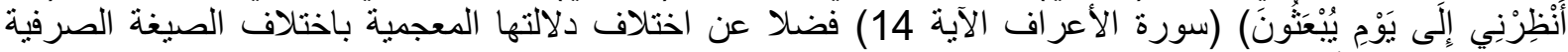

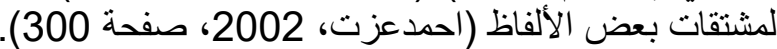

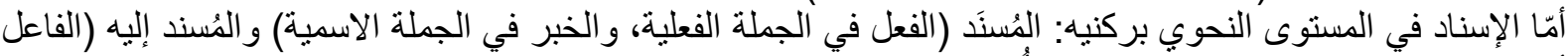

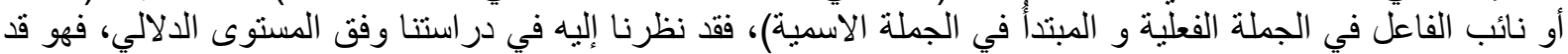

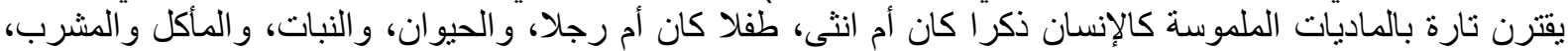

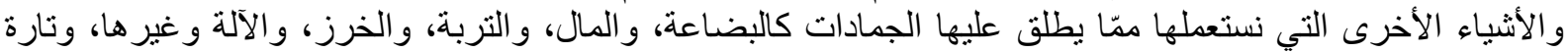

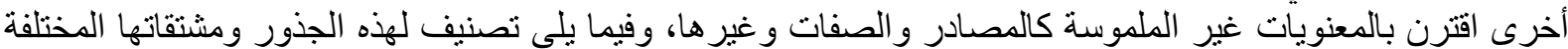

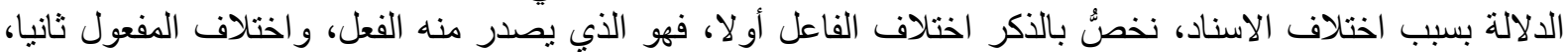

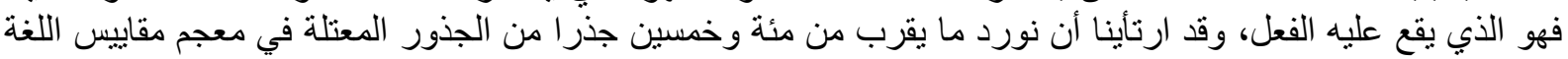

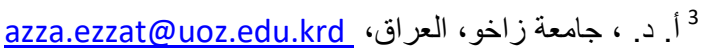
4 
لتوضيح الفكرة، والنظر فيها، فالقصد هو طرح وجهة النظر، ويمكن أن تلحق هذه الدراسة بدراسة أخرى تتعلق بالجذور الصحيحة، أو الجذور المهموزة، أو المعاجم الأخرى، بيد أننا تناولنا معجم مقاييس اللغة بونة بوصفه معجما يتناول الأصول اللغوية العامة للجذور.

الهكف من الدراسة الألة

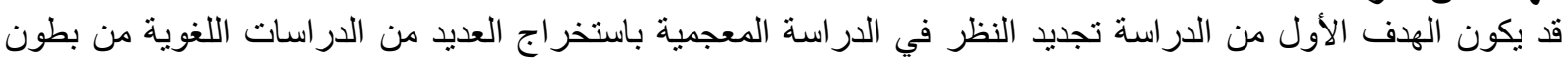

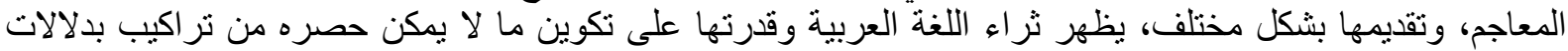

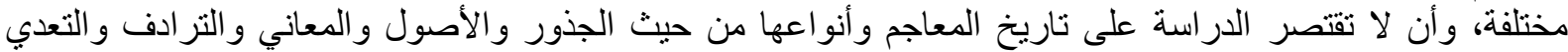

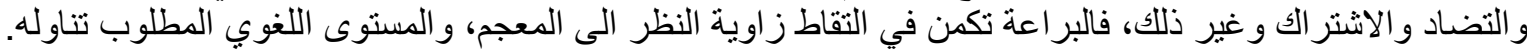

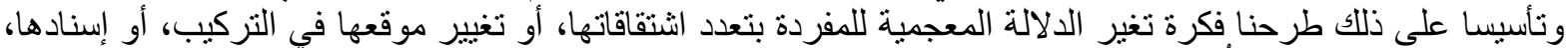

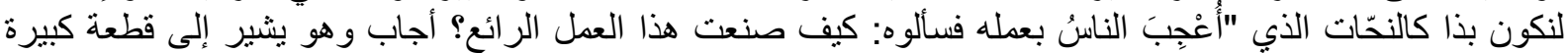

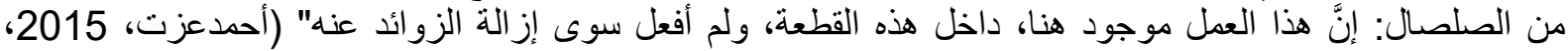

صفحة 260).

الاراسة التطبيقية

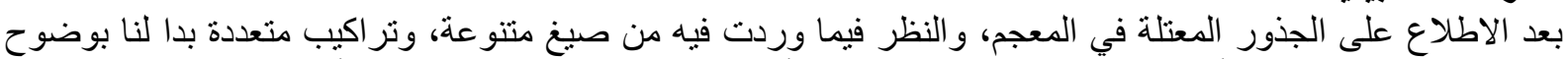

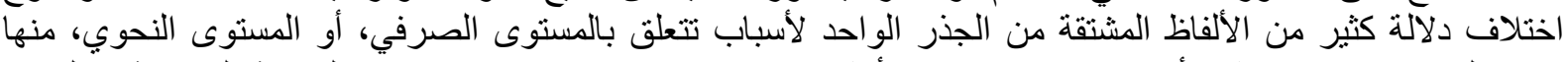

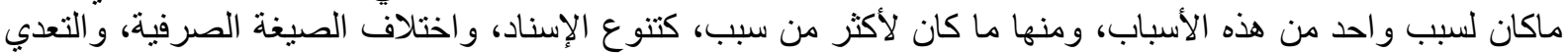

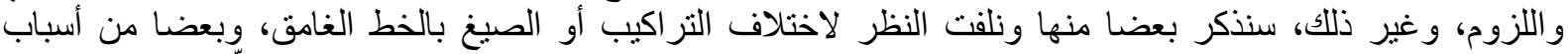

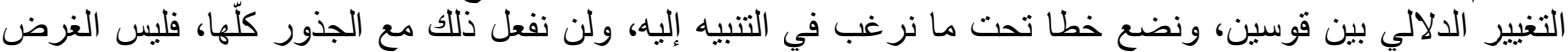
التوضيح بقر الرغبة في تفاعل القاريء، وعصف ذهنه من خلال النظر في التغيّر الدلالي، ومحاولة إثراكه في في استكثاف أسباب ذللك الاختلاف فئ. 1) (أنو): (زكريا، 1979، صفحة 1:49) الهمزة و التاء و الواو والألف والياء، يدلُ على (مجيء الثيء و إصحابِه

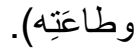

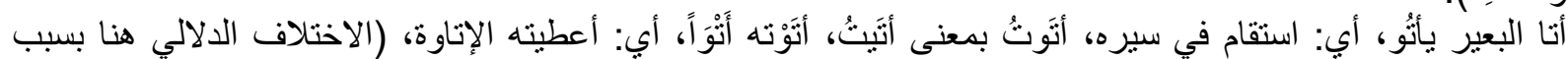

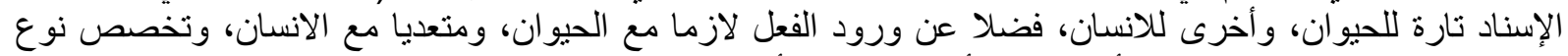

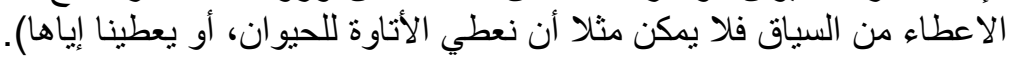

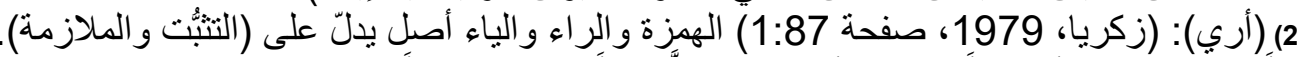

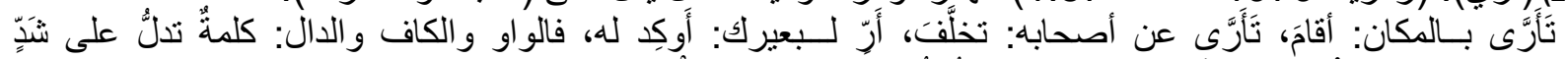

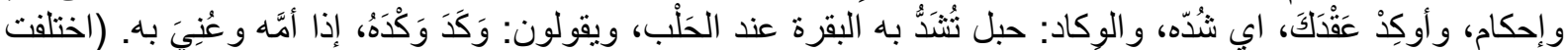

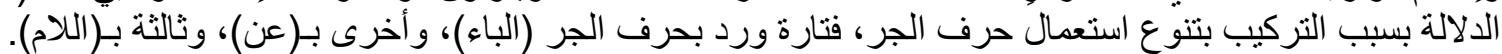

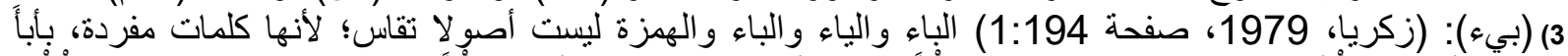

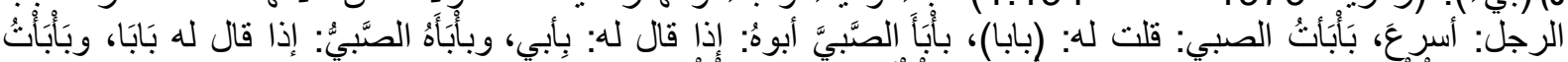

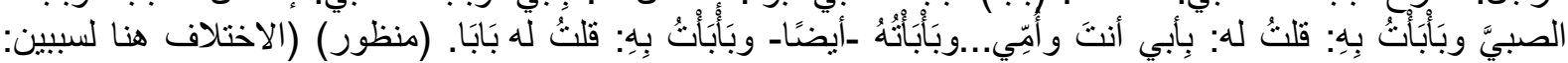

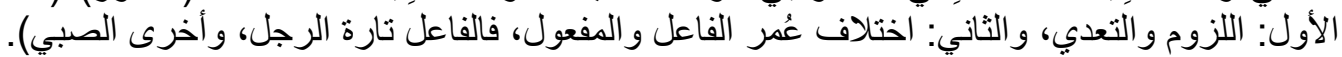

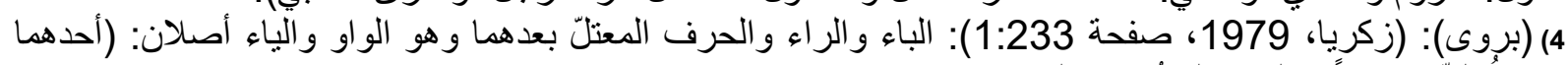

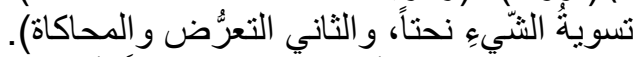

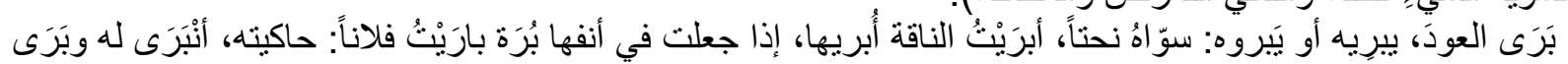

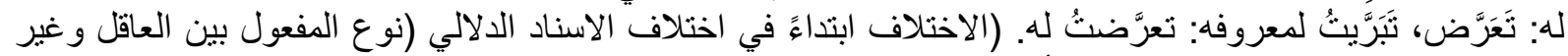

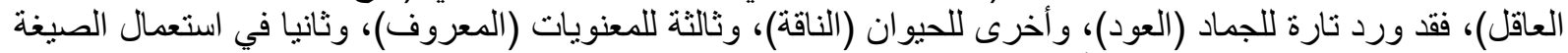

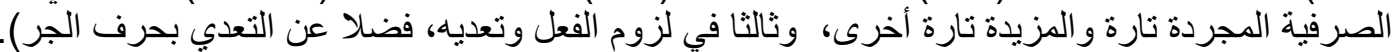

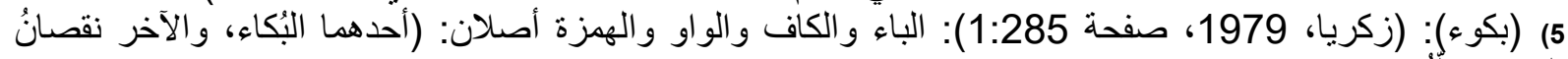

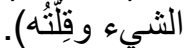

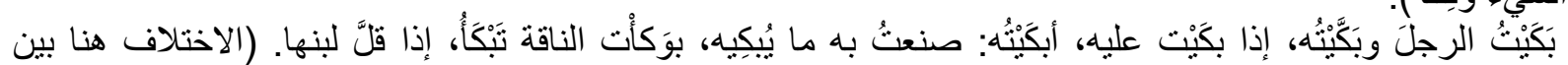

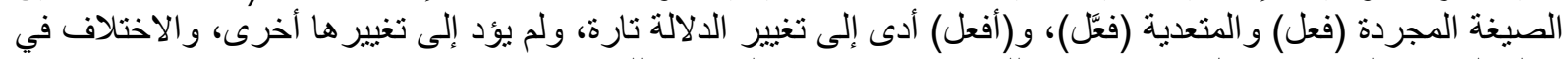

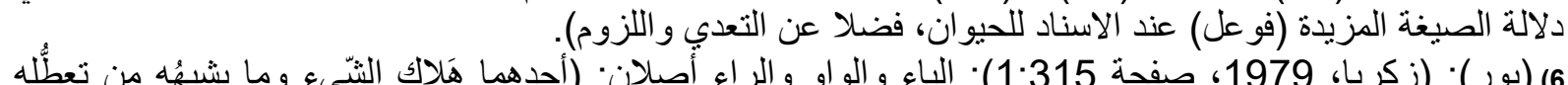

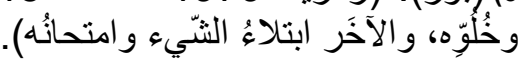




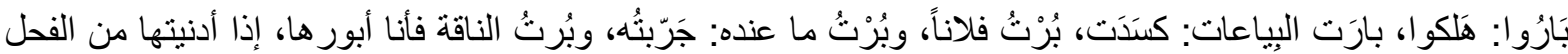

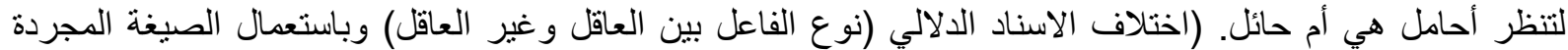

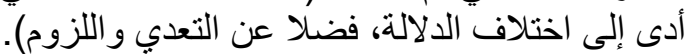

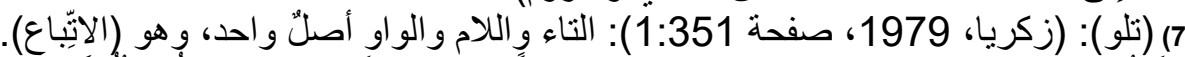

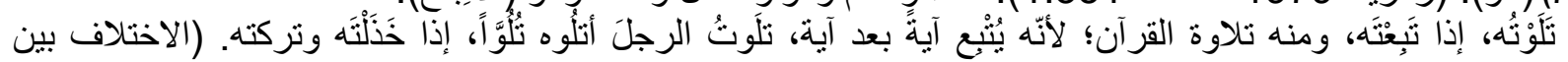

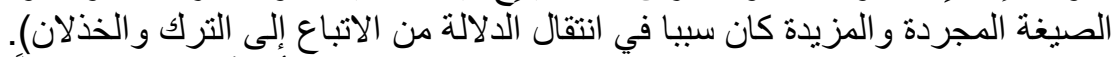

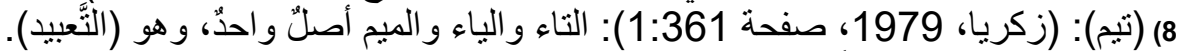

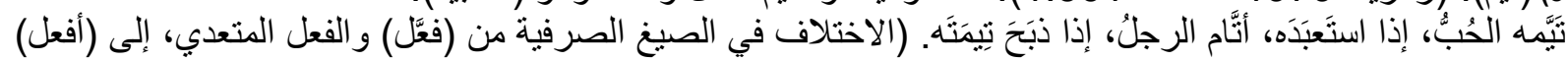

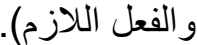

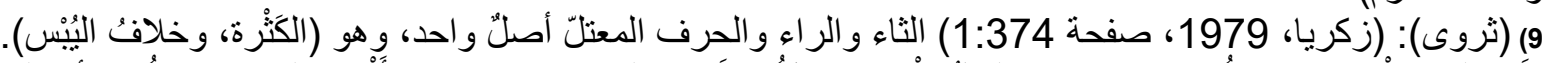

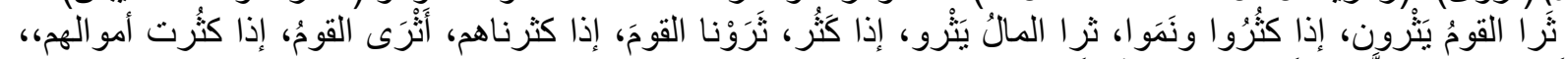

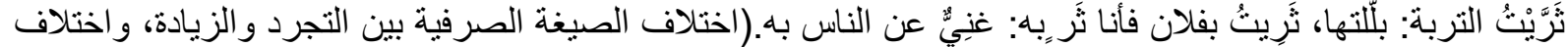

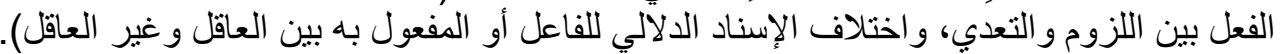

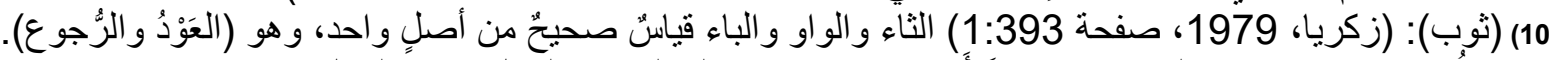

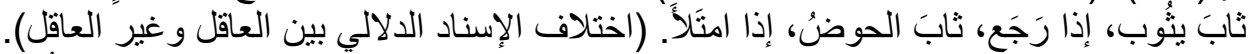

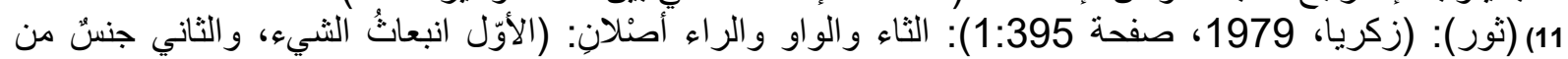

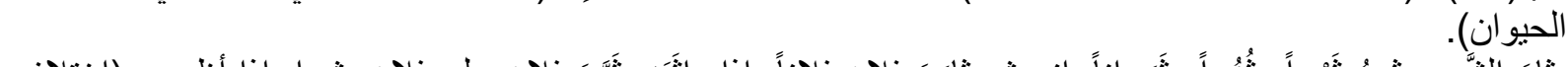

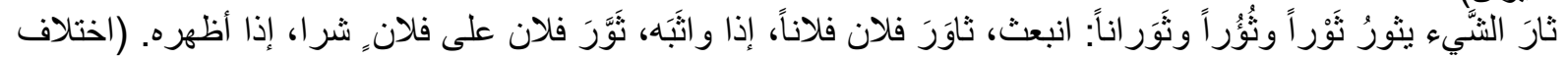

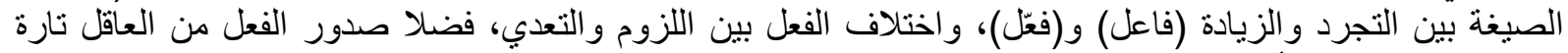
ومن غير العاقل تارة أخرى).

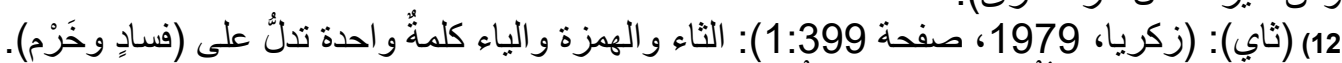

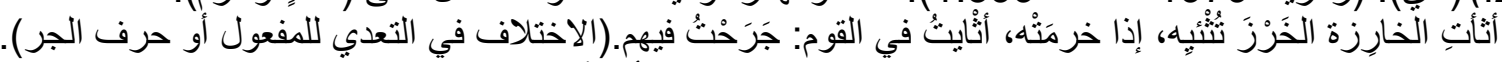

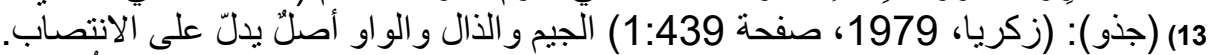

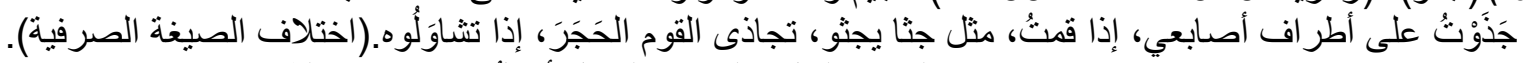

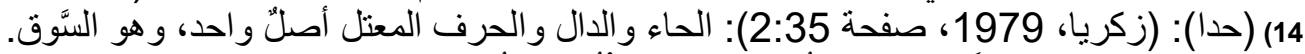

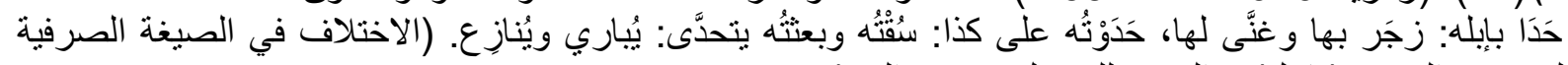

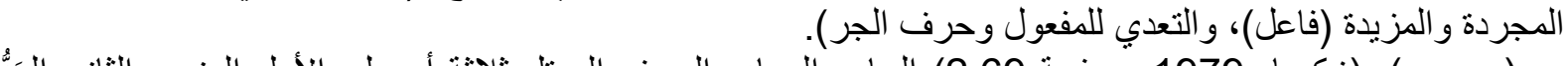

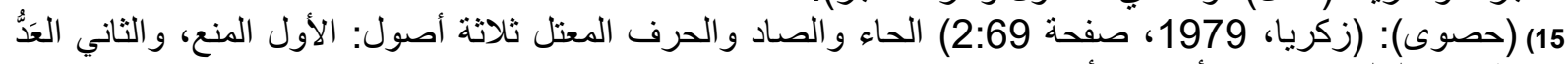

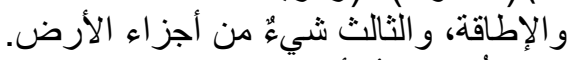

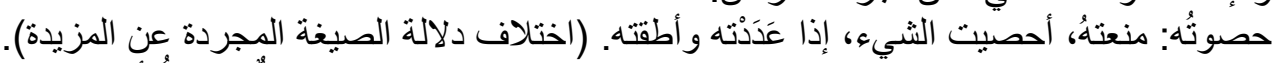

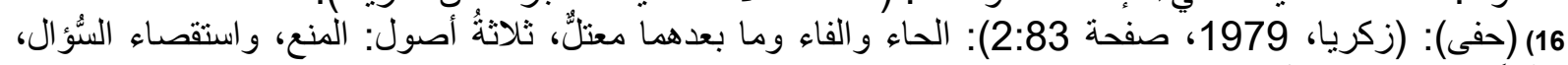

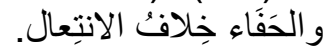

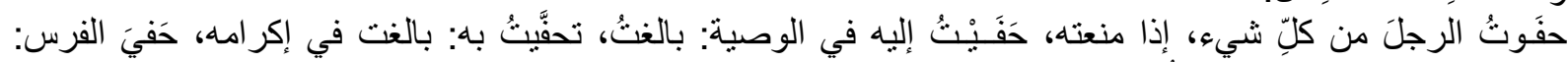

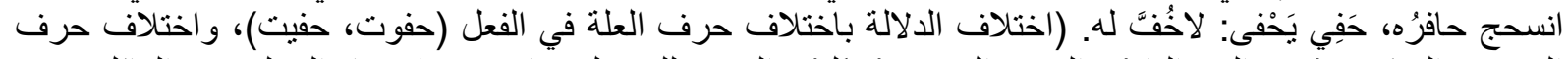

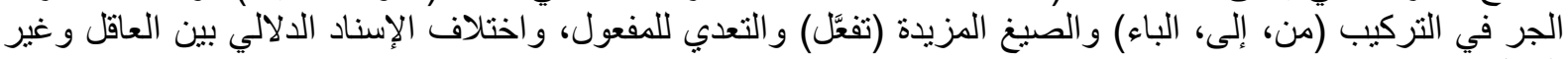

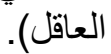

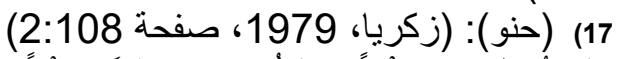

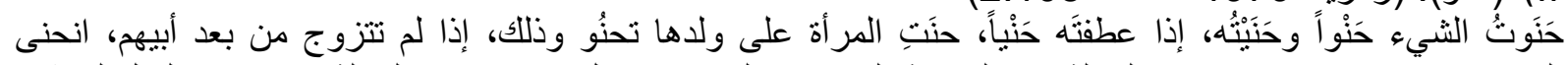

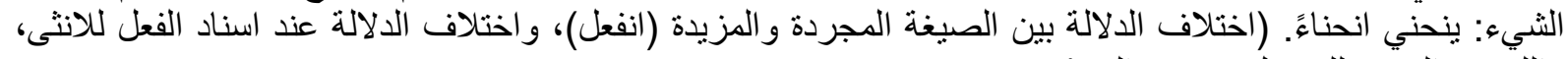

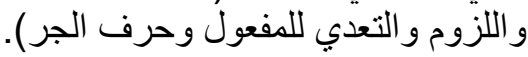

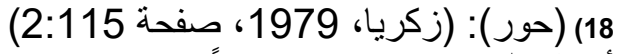

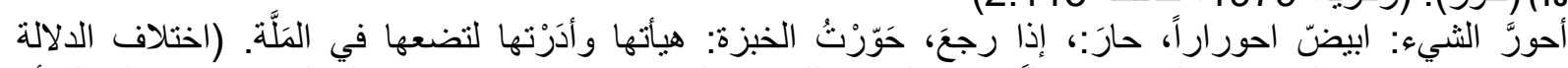

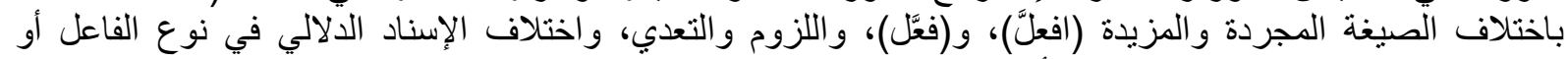

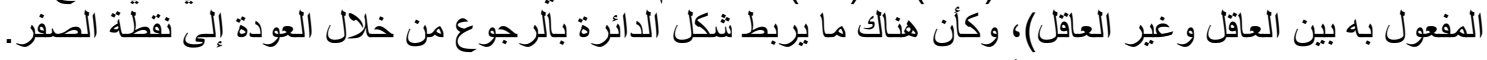

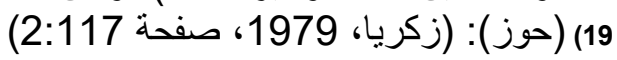




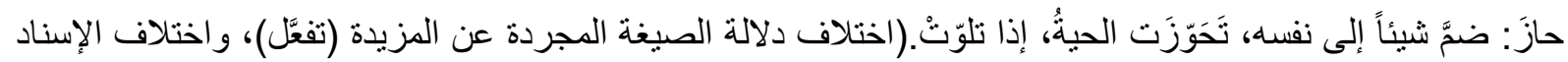

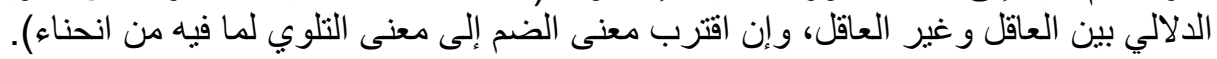

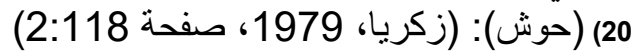

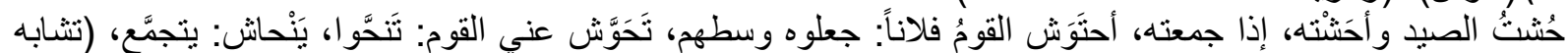

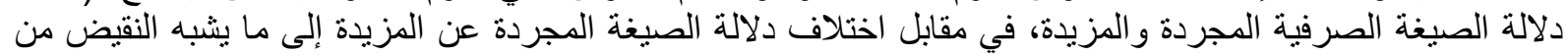

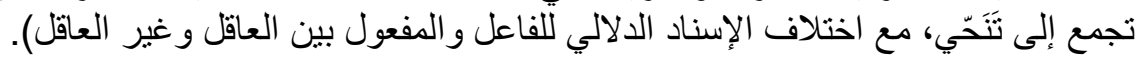

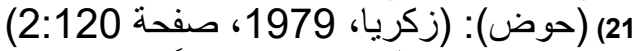

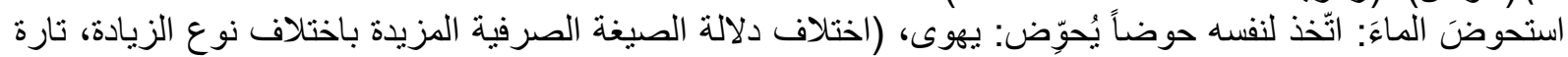
بحرف، و أخرى بثلاثة أحرف) النغاء).

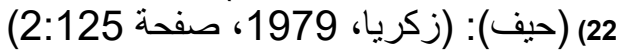

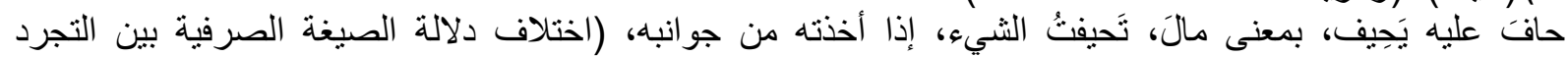

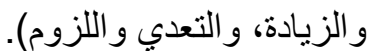

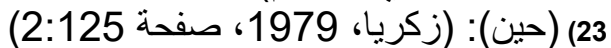

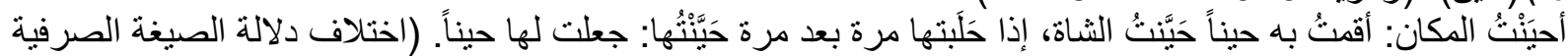

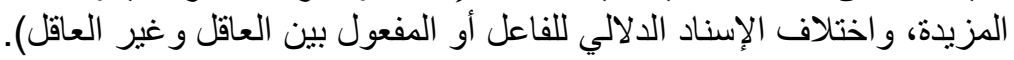

24) (حبو): (زكريا، 1979، الإن صفحة 2:132)

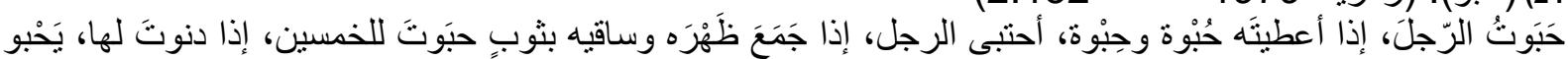

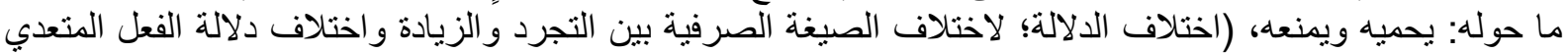

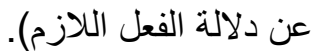

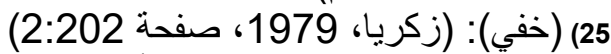

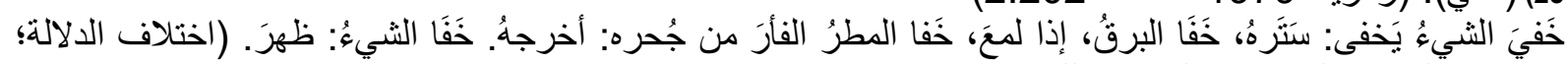

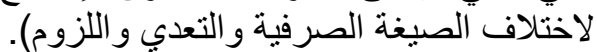

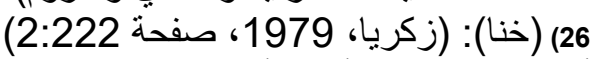
أخنَى عليه الدهر: أهلكَه أخنى فلان في كلامه: أفحشَ، (اختلاف الدلالة؛ لاختلاف الإسناد الدلالي بين العاقل وغير العاقل،

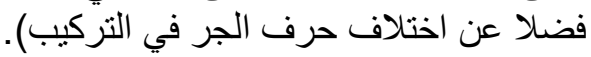

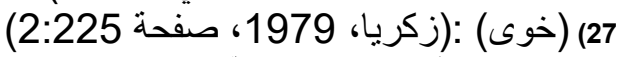

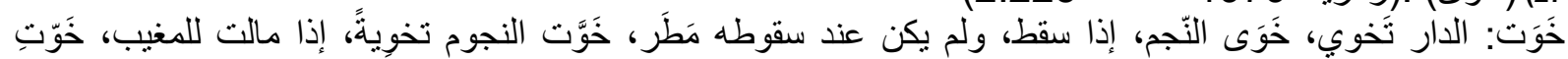

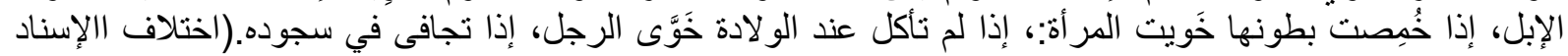

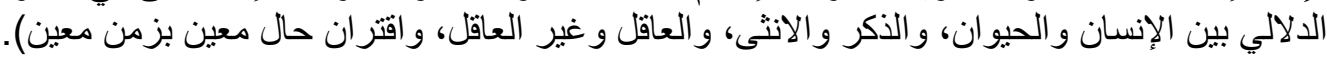

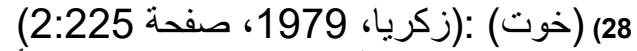

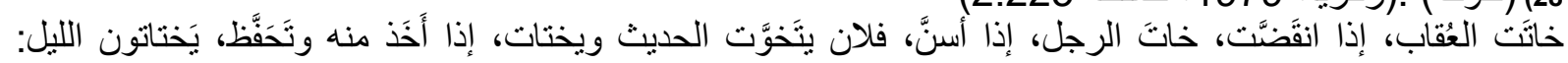

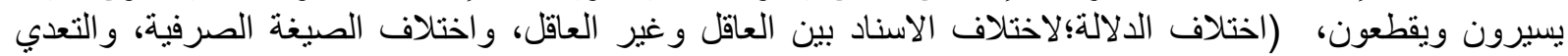

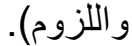

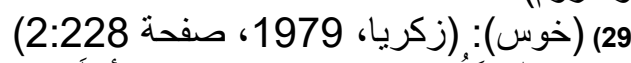

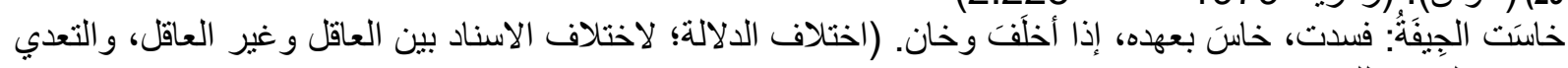
بحرف الجر واللزوم).

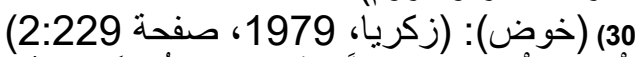

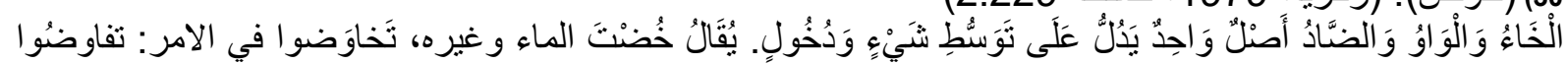

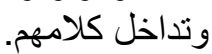

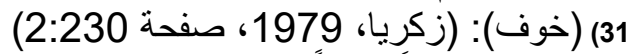

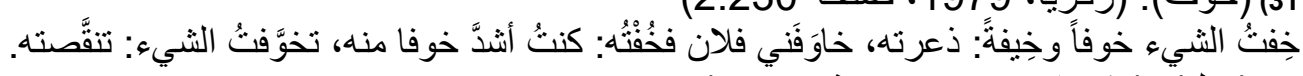

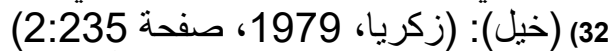

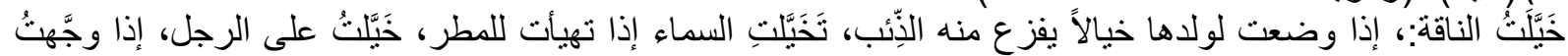

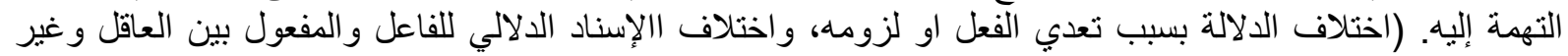

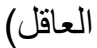

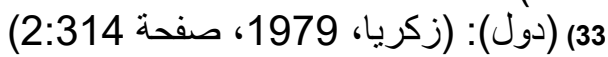

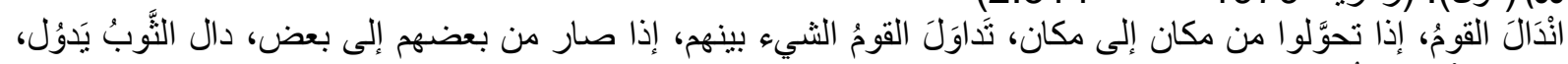

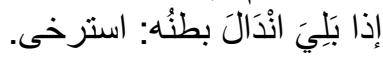

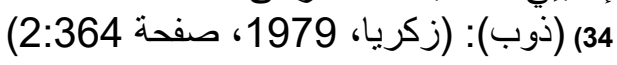




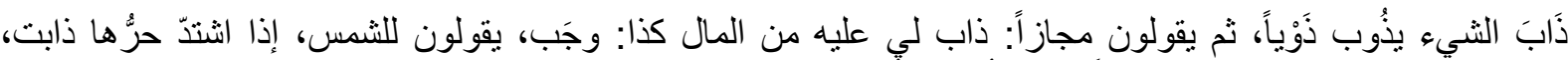

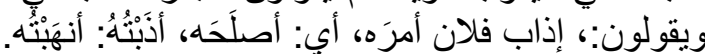

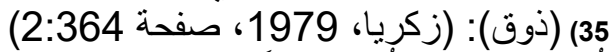

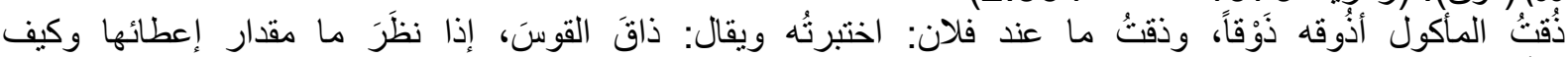

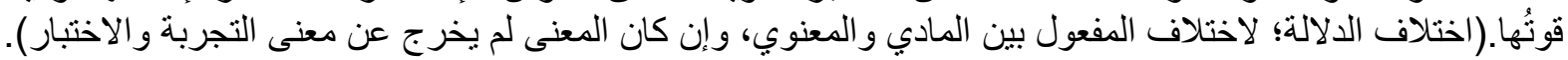

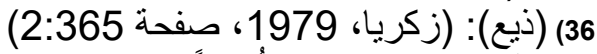

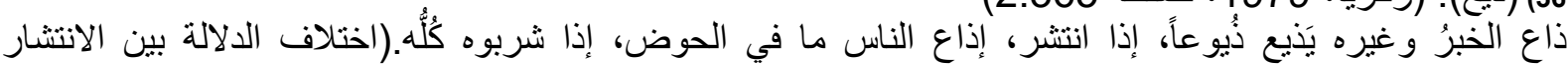

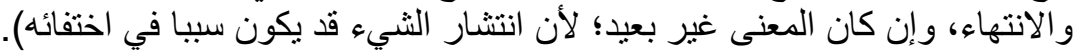

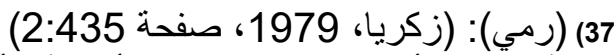

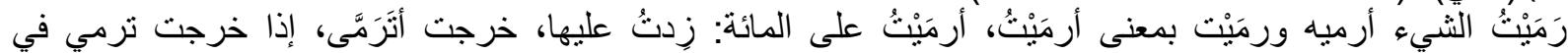

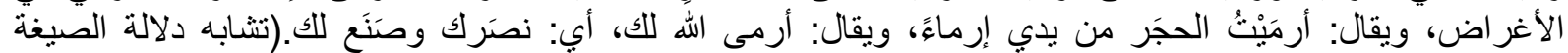

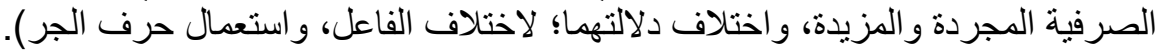

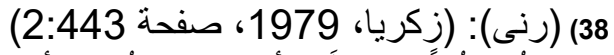

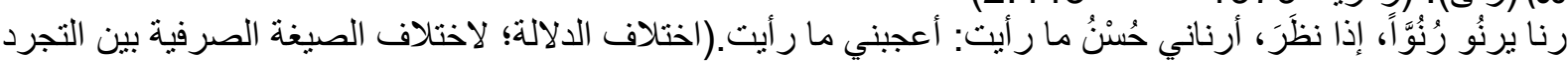

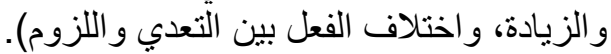

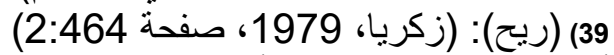

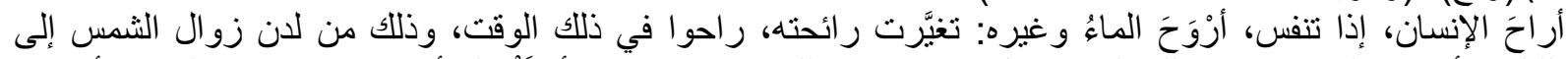

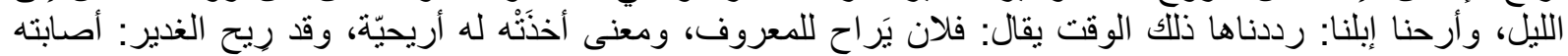

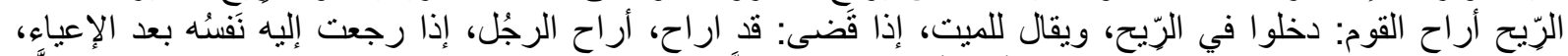

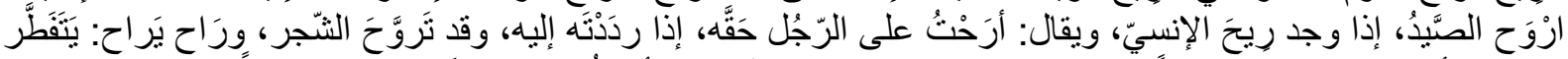

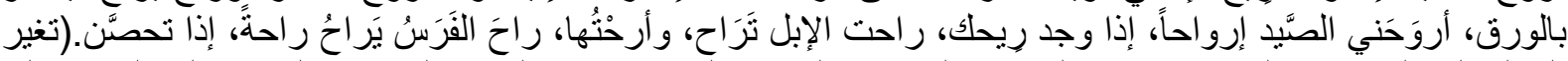

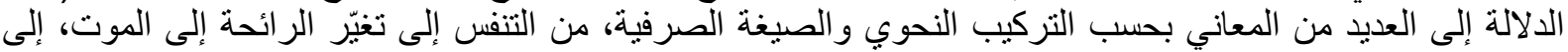

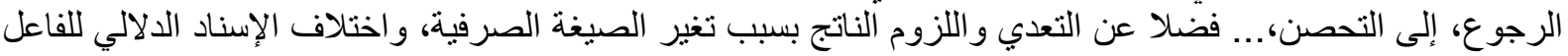

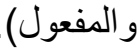

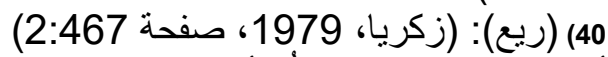

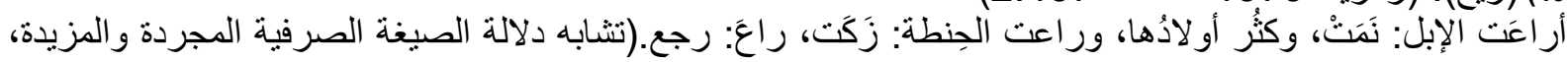

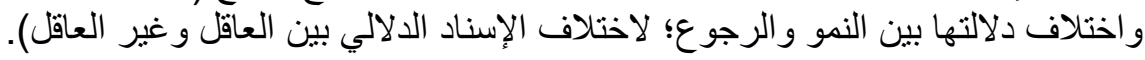

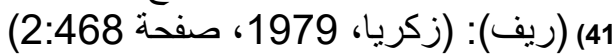

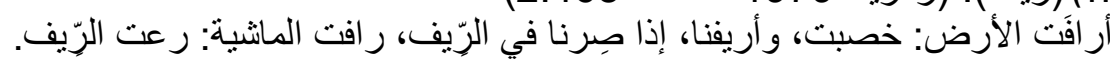

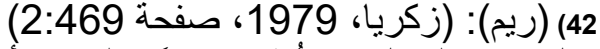

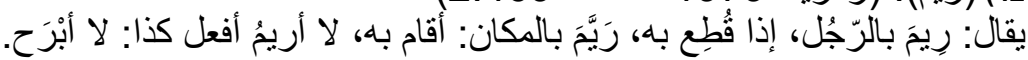

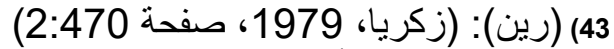

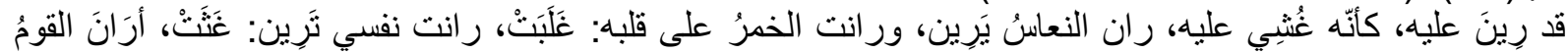

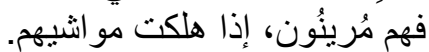

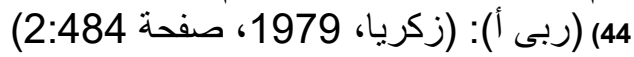

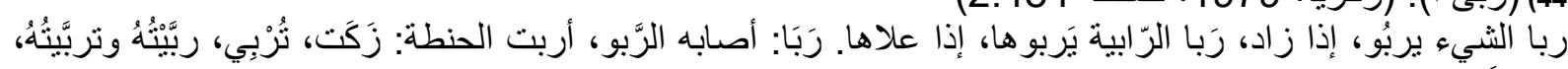

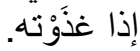

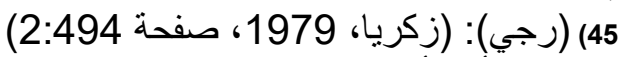

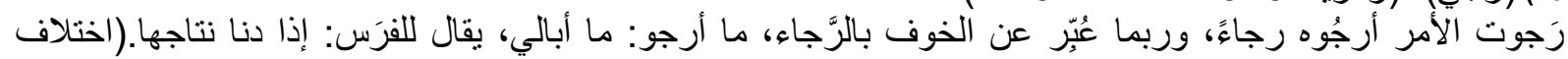

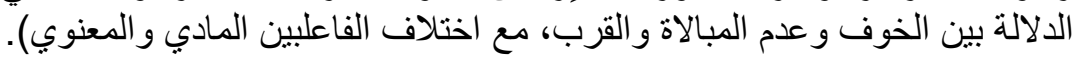

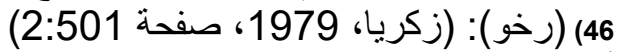

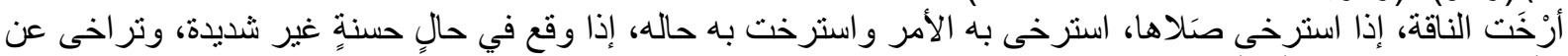

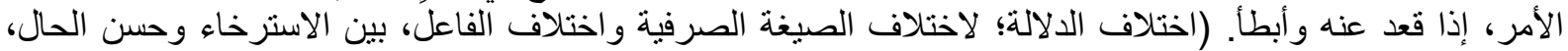

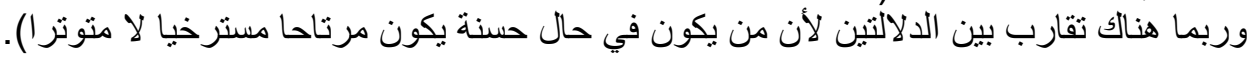

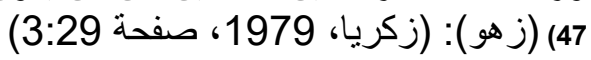


زُهِيَ الرجل، إذا تفخر وتعظَُّ، زَهَت الريحُ النبات، إذا هَزَّنه. (اختلاف الدلالة؛ لاختلاف الإسناد الدلالي بين العاقل و غير

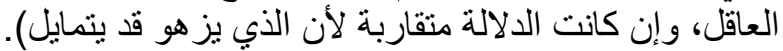

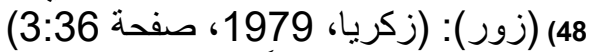

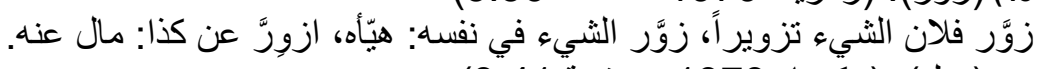

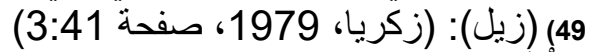

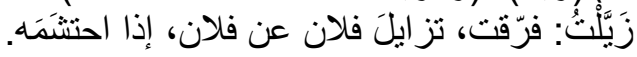

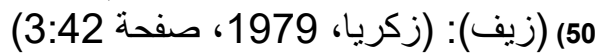
زافت الجمل في مشيه يزيف، (زئ، إذا اسرع، المر أة تزيف في مشيها: نستدير. (اختلاف الدلالة؛ لاختلاف الإسناد الدلالي بين العاقل و غير العاقل).

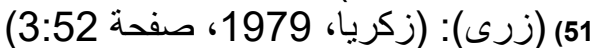

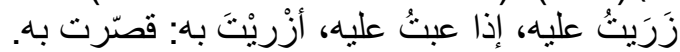

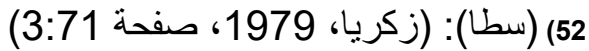

سطا عليه يسطو، (إذا قهره، سطا الماء، إذا كثر، سطا الراعي على الثشاة، إذا مات ولأها في بطنها فسطا عليها

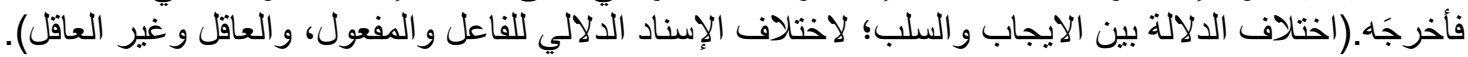

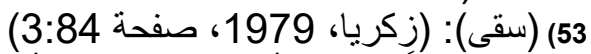

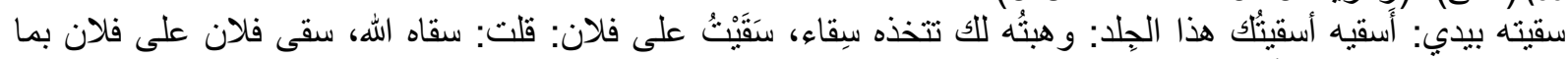

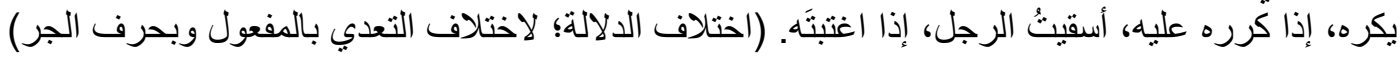

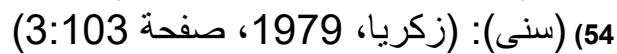
سَنَتِ الناقة، إذا سقت الأرضا، سون، سانيت الرجل: إذا راضيتُّه. (اختلاف الدلالة؛ لاختلاف الصيغة بين التجرد و الزيادة،

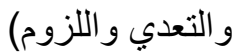

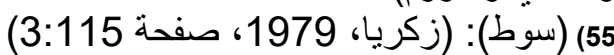

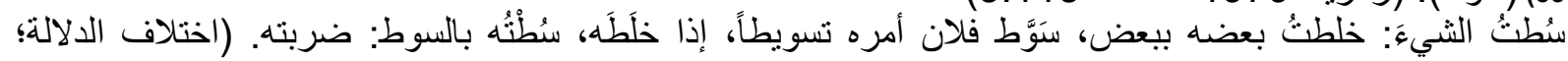

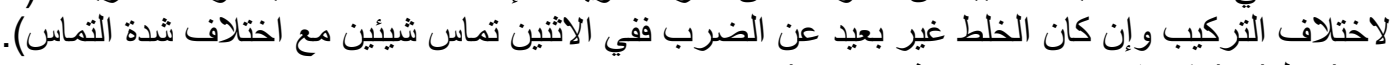

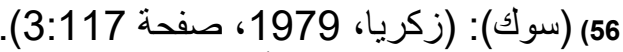

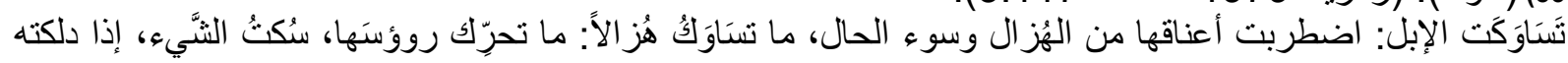

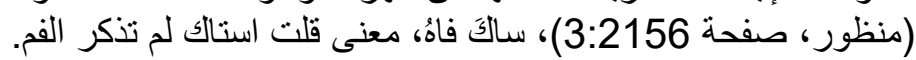

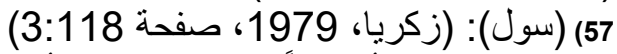

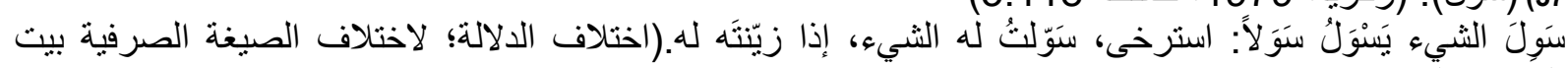

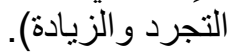

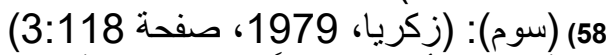

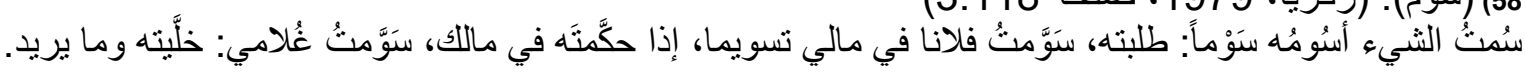

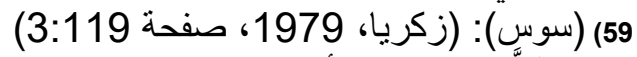

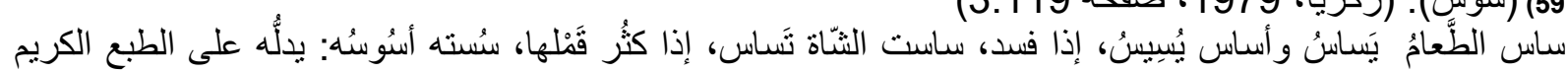
وَيَحمِله عليه.

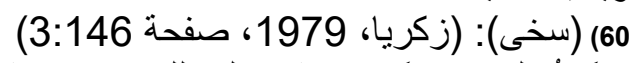

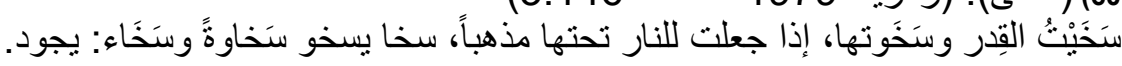

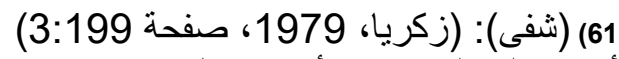

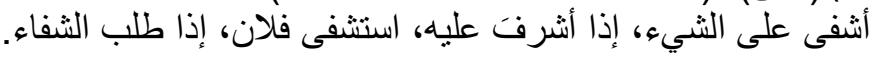

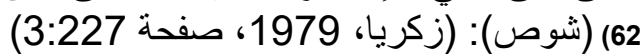

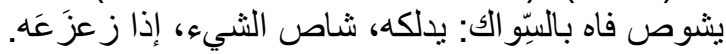

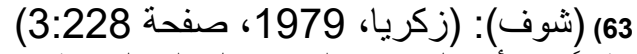

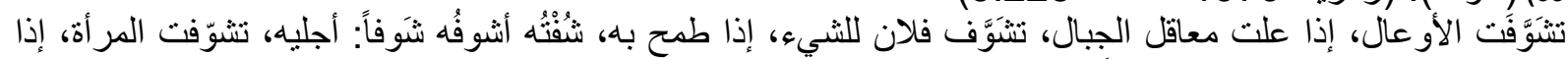

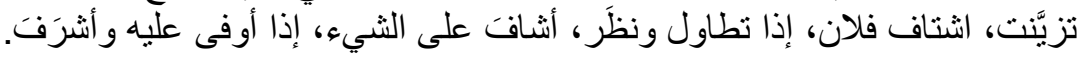

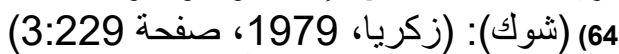

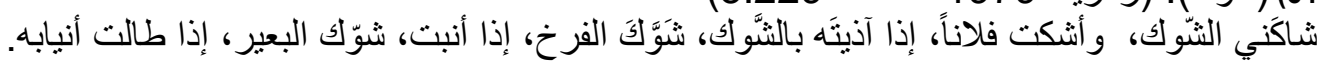

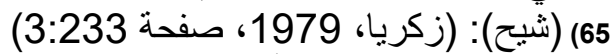

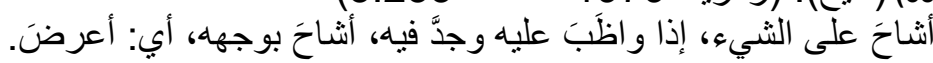

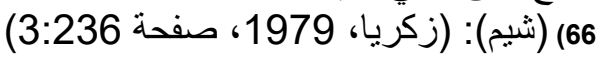




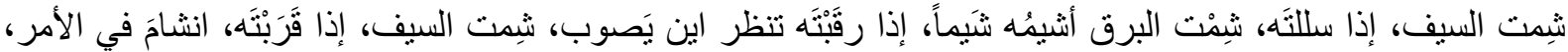

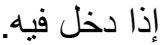

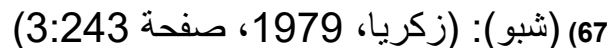

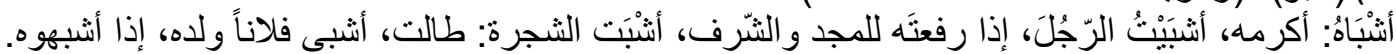

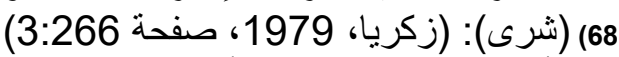

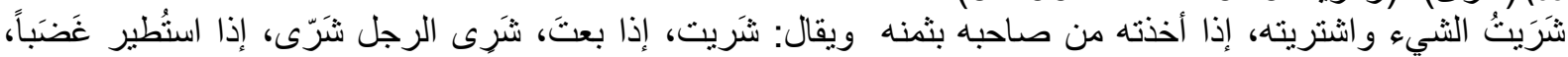

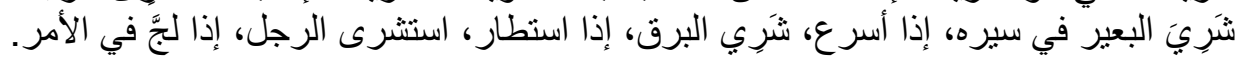

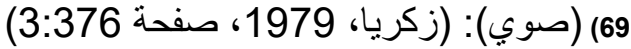

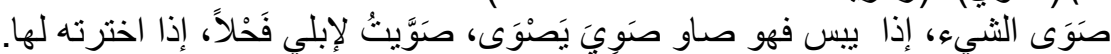

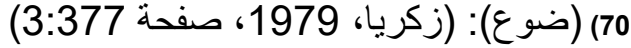

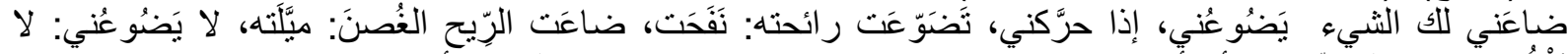

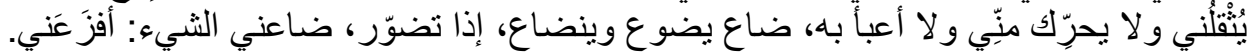

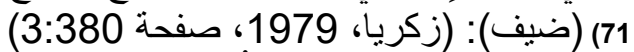

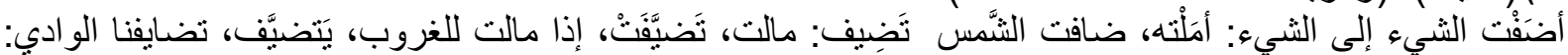

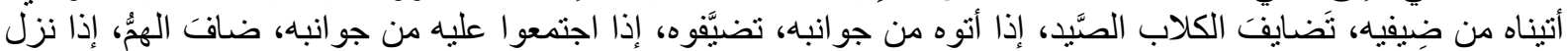
بصاحبه.

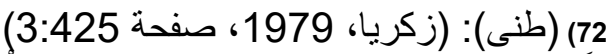

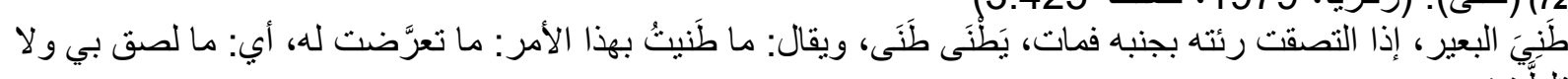

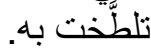

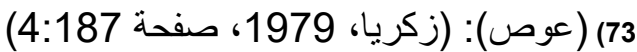

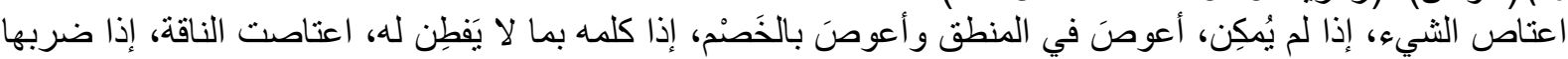

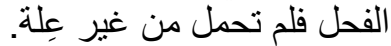

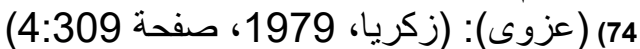

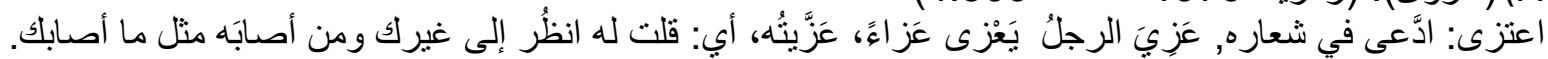

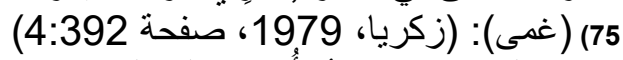

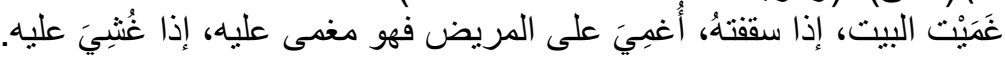

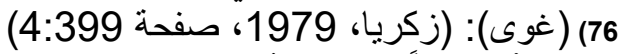

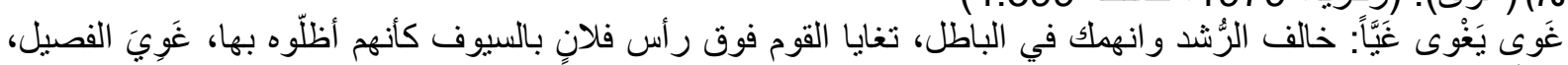

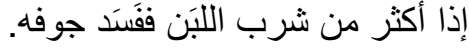

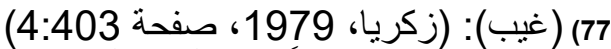

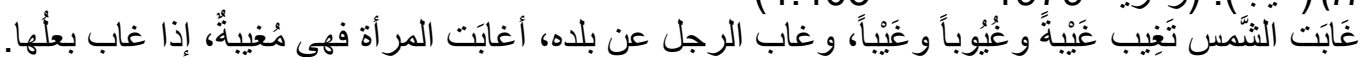

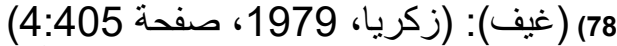

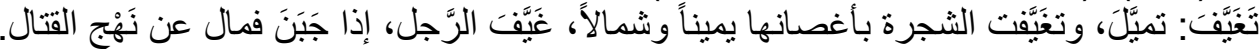

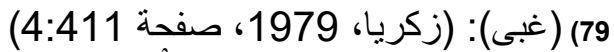

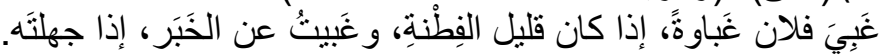

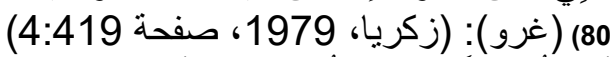

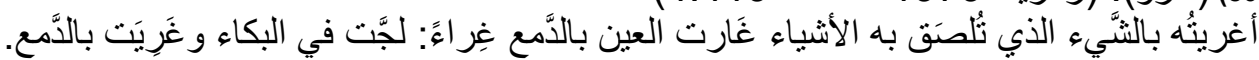

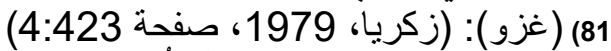

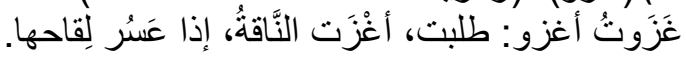

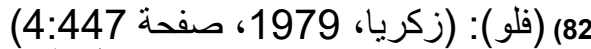

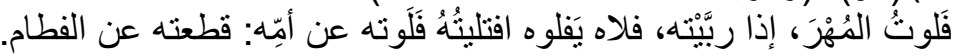

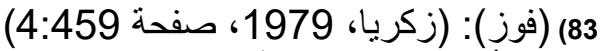

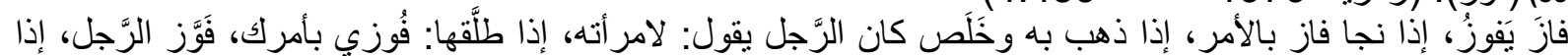

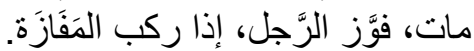

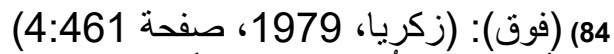
فاق أصحابَه يفوقُهم، إذا علاهم أفاقَ السَّكران: يُفيقُ وذللك من أَوبةِ عقله إلبه. 


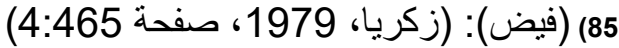
فاضَّ الماءُ: يفيضُ أفاضَ القوم في الحديث، إذا اندفعو ا فيه، أفاضنَ البعير بجِرَّنه، إذا دفع بها من صدره، فاضَ الرَّجل، إذا

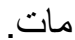

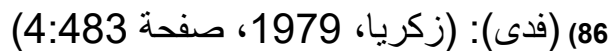

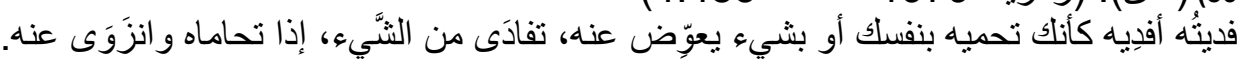

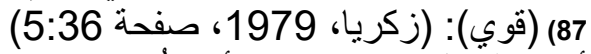

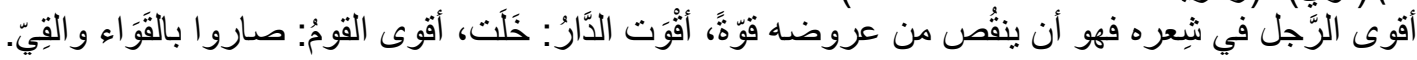

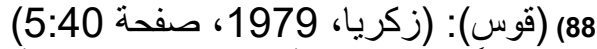

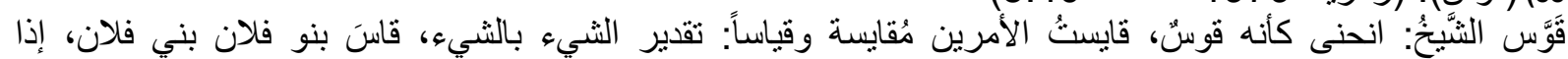
سبقو هم.

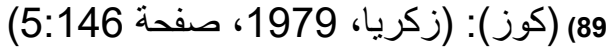

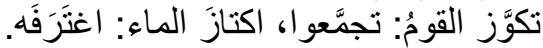

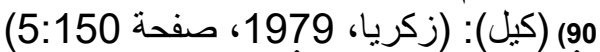

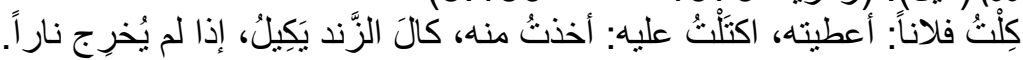

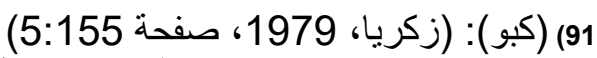

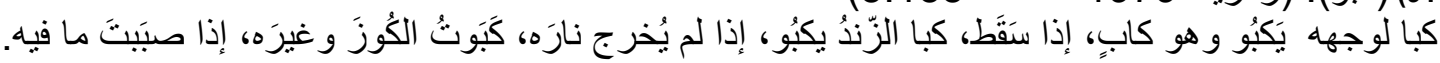

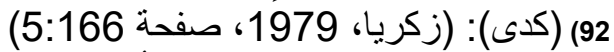

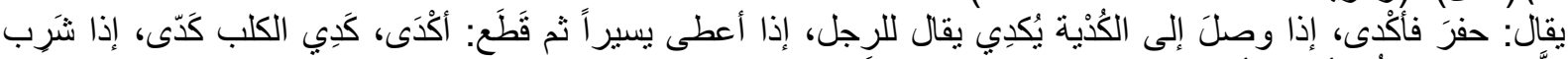

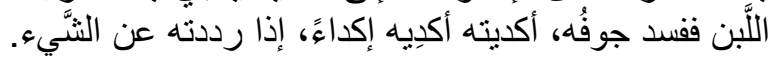

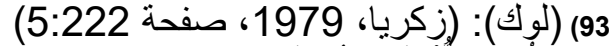

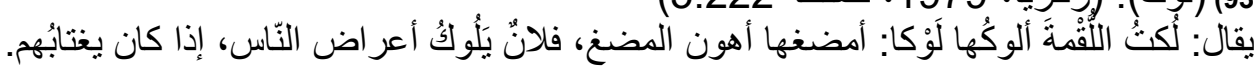

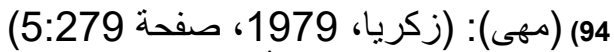

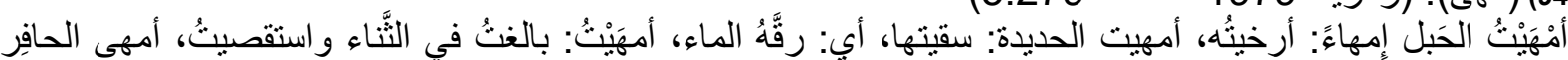

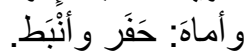

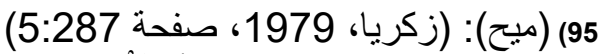

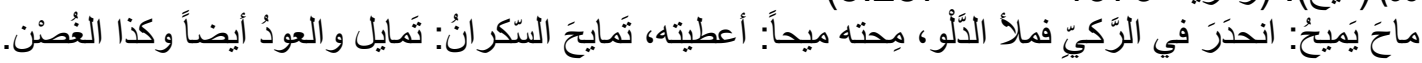

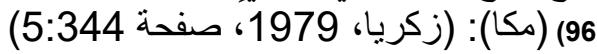

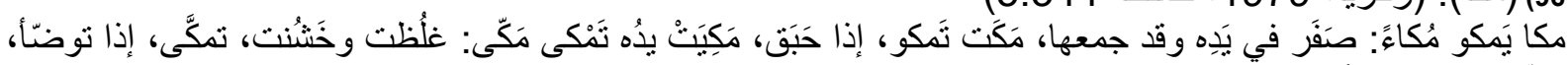

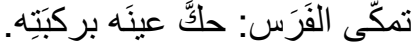

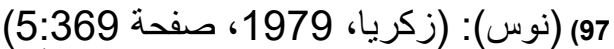

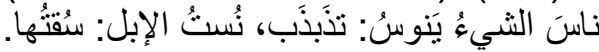

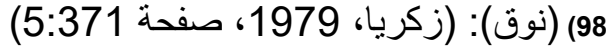

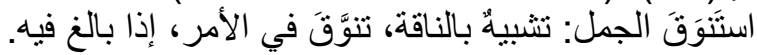

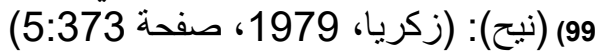

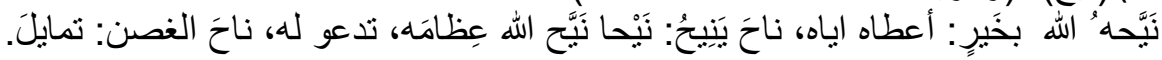

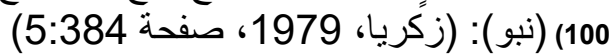

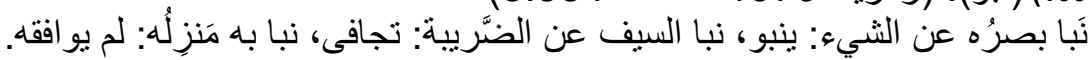

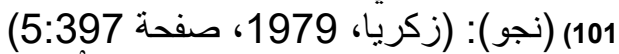

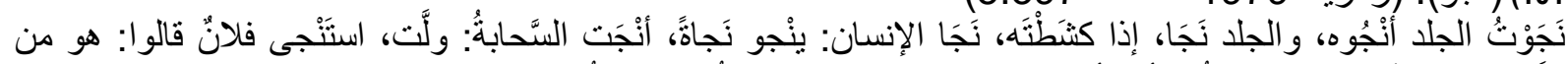

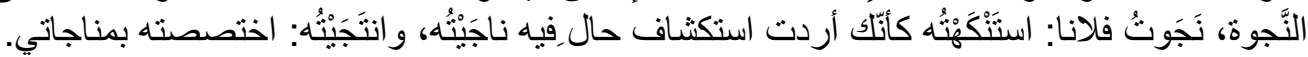

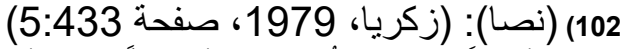

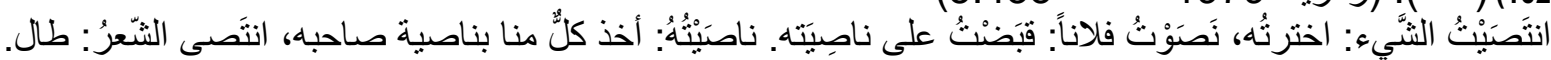
103) (نضا): (زكريا، 1979، 19: صفحة

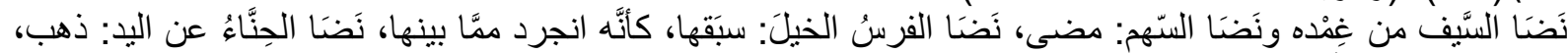

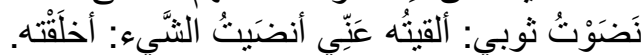

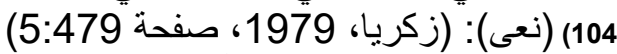

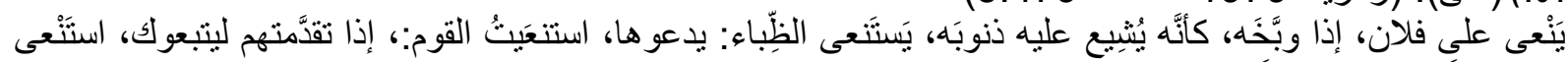

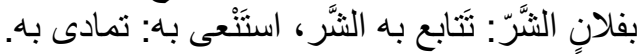

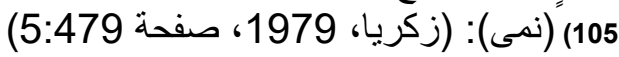




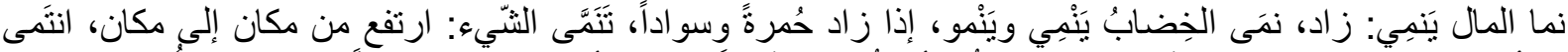

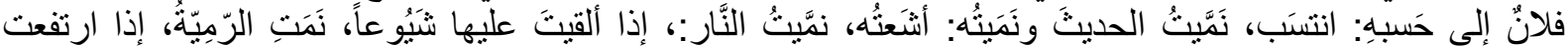

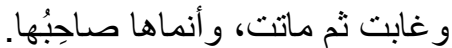

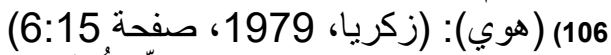

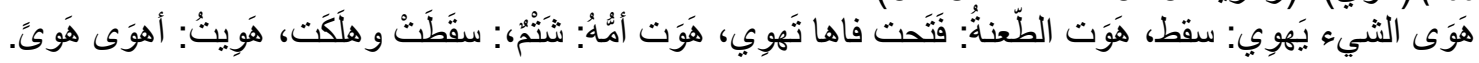

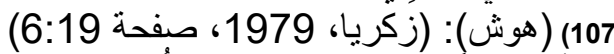

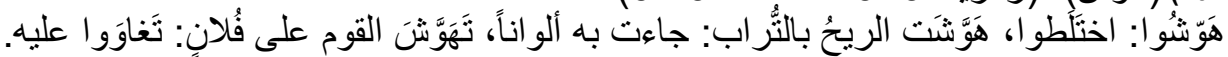

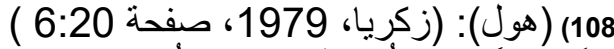

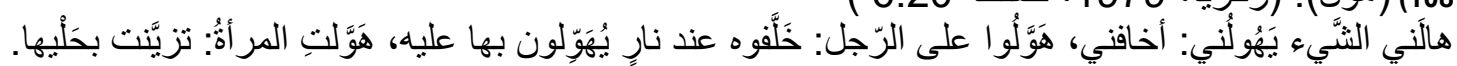

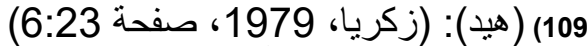

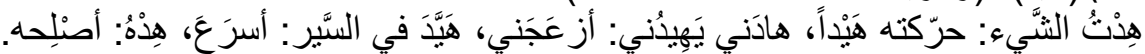

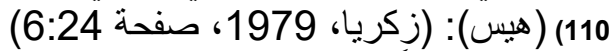

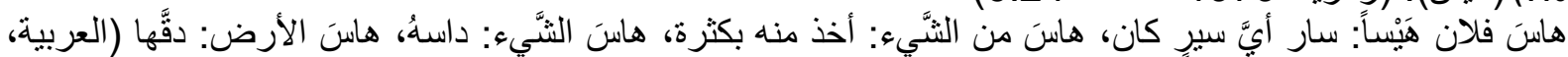

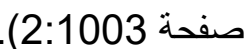

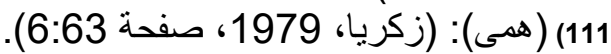

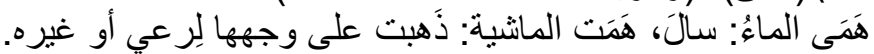

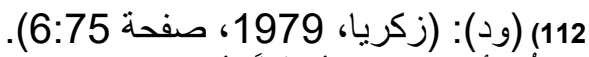

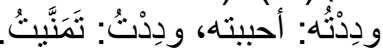

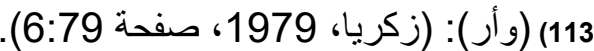

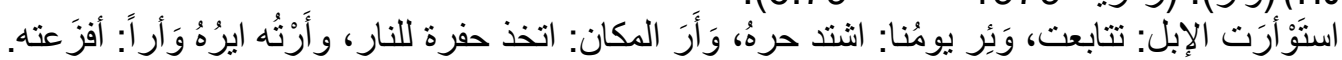

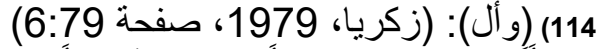

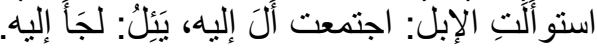

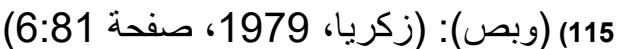

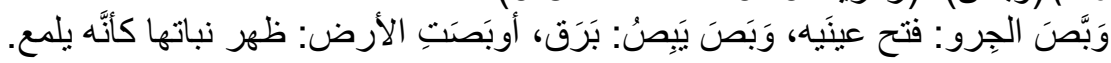

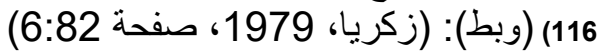

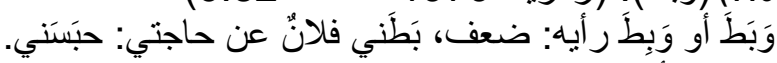

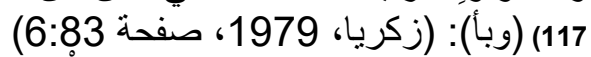

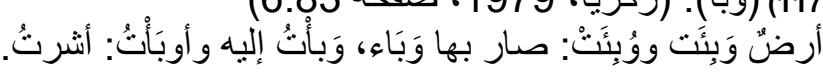

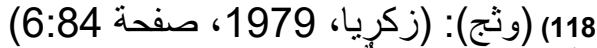

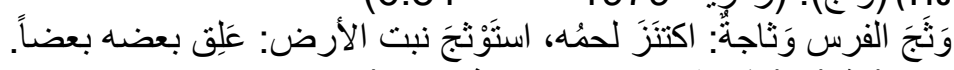

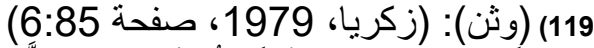

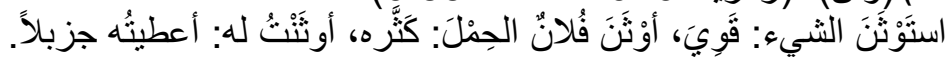

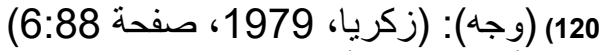

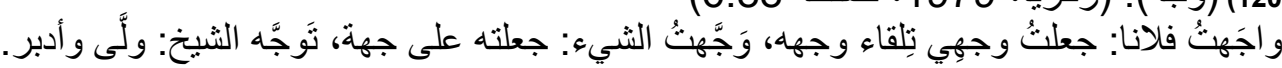

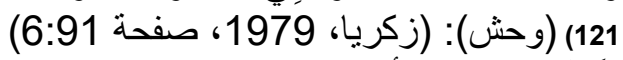

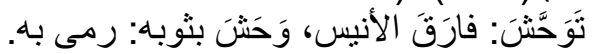

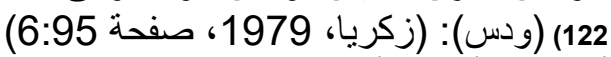

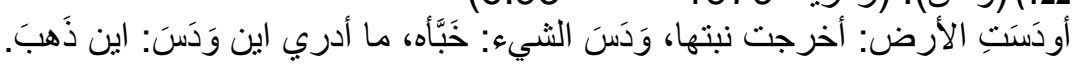

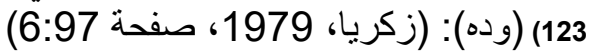

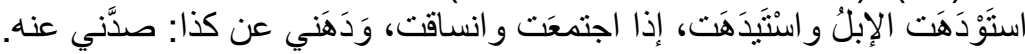

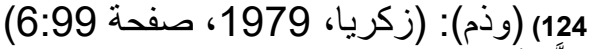

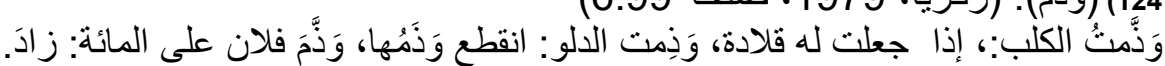

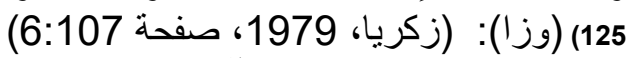

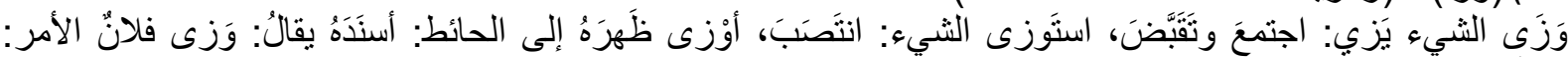

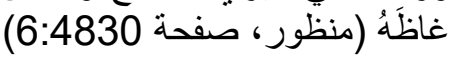
126) (وزر): (زكريا، 1979، (رفية صفحة 6:108) 


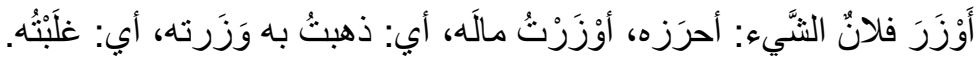

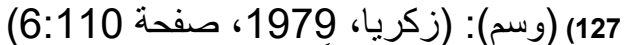

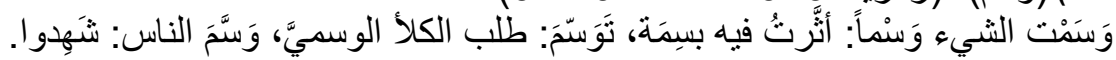

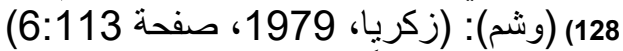

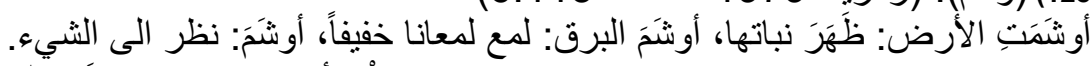

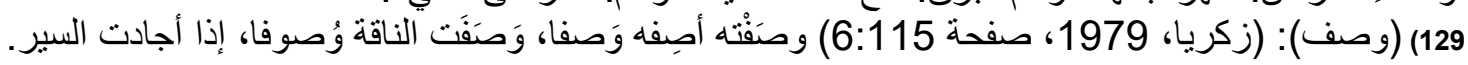

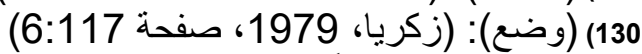

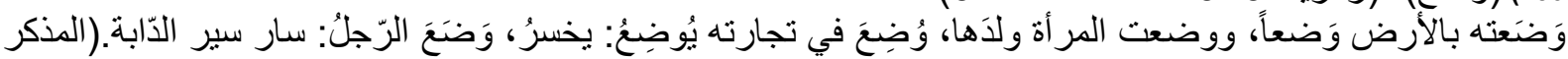

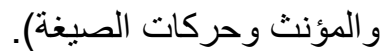

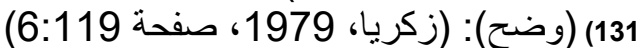

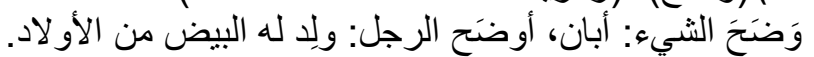

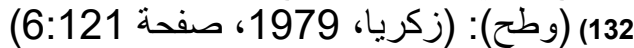

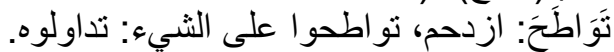

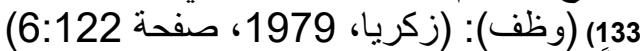

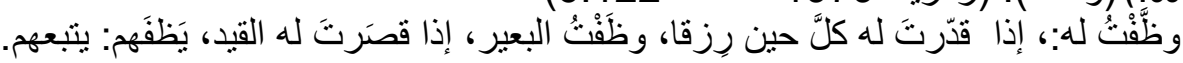

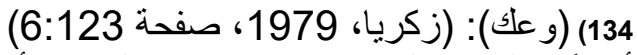

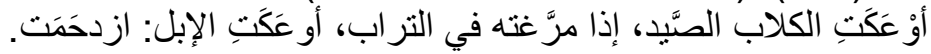

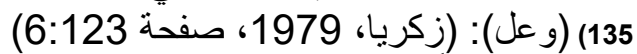

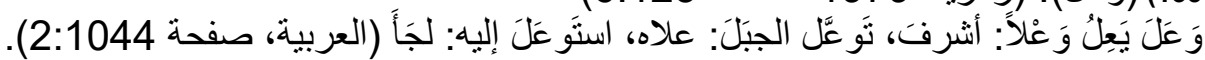

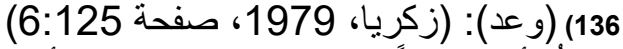

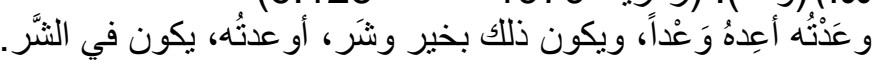

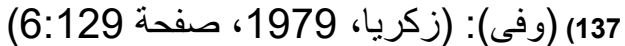

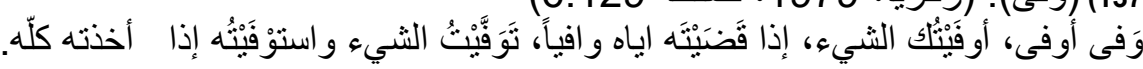

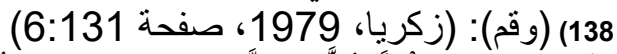

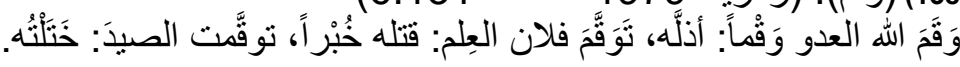

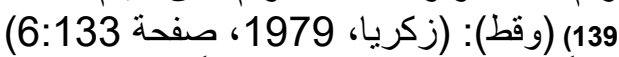

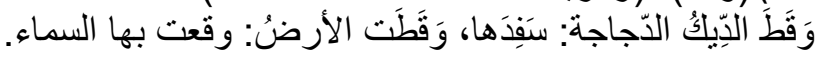

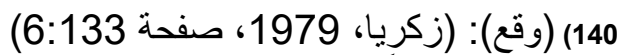

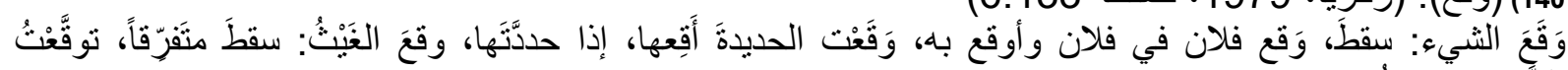

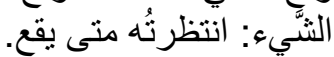

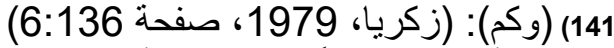

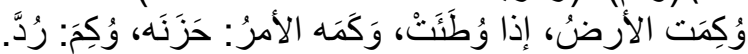

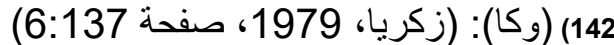

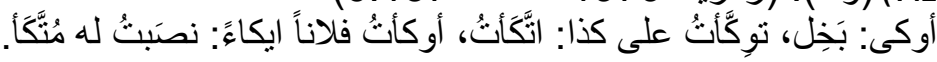

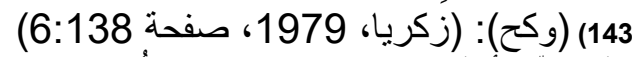

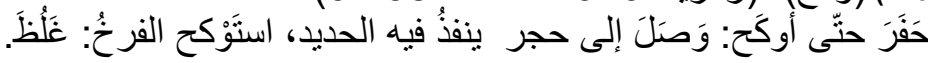

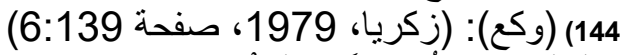

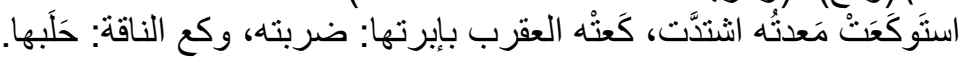

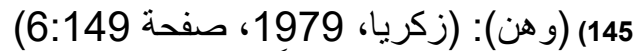

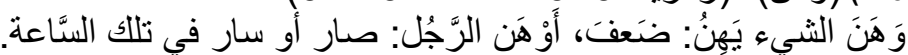

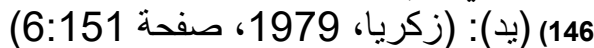

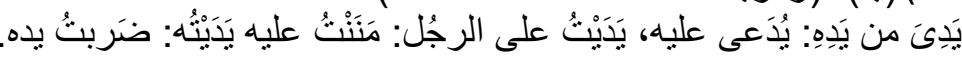

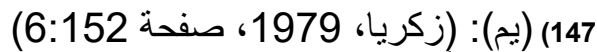

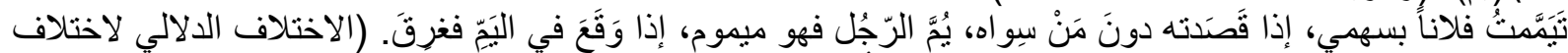

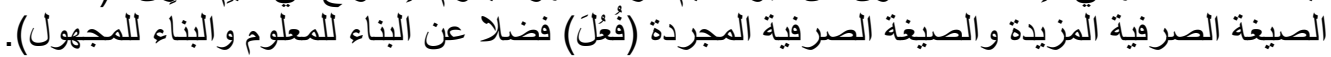

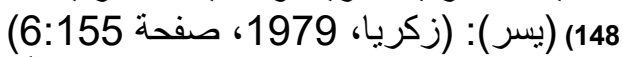

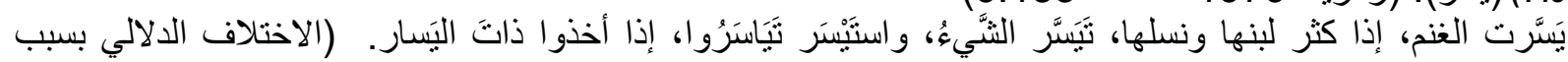

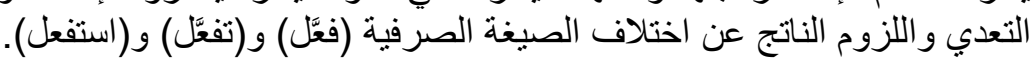


لا يصح الفصل بين المستويات اللغوية في أية دراسة لغوية متكاملة، ولاسيما الدراسات الني تتعلق بتغير الدلالة بتغير

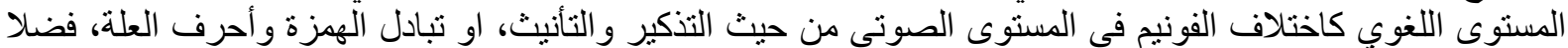

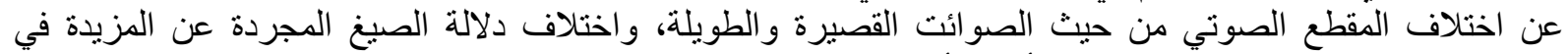

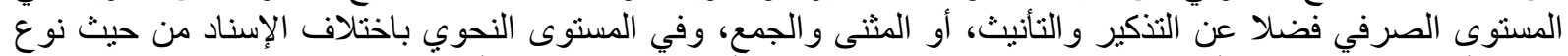

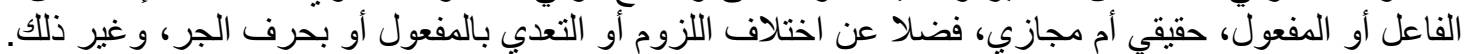

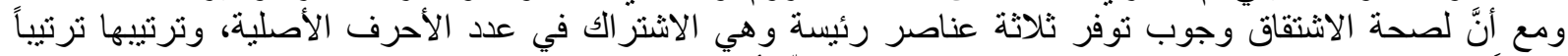

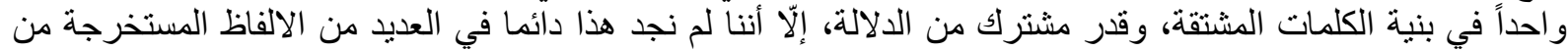

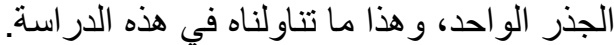

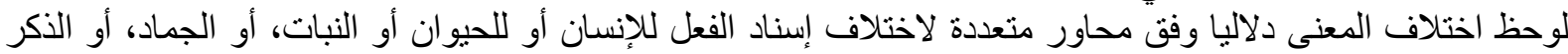

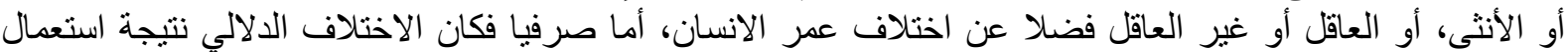

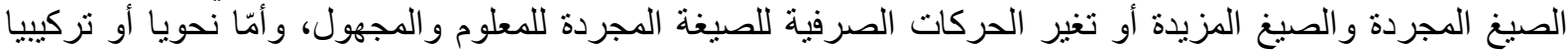

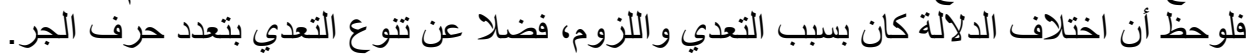

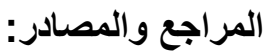

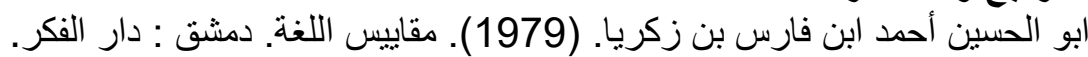

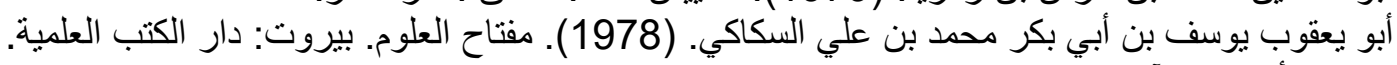

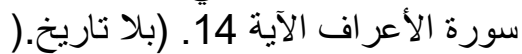

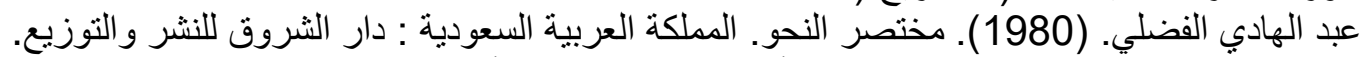

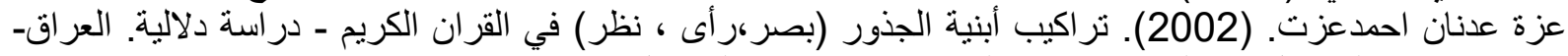

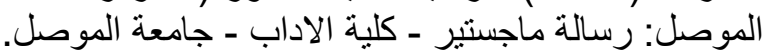

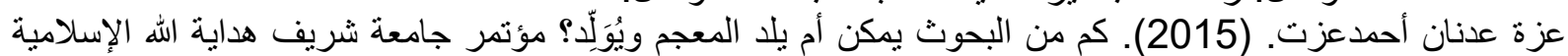

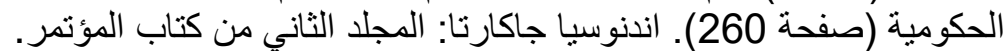

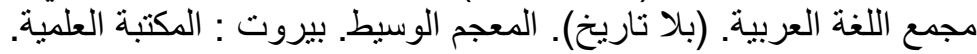

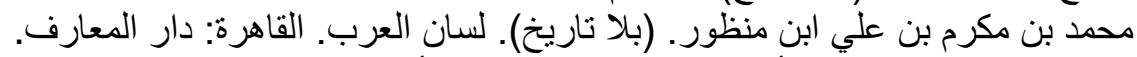

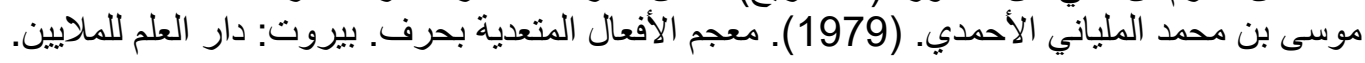

